\title{
hsa-miR-9-3p and hsa-miR-9-5p as Post-Transcriptional Modulators of DNA Topoisomerase Il $\alpha$ in Human Leukemia K562 Cells with Acquired Resistance to Etoposide
}

\author{
Evan E. Kania, Jessika Carvajal-Moreno, Victor A. Hernandez, Anthony English, \\ Jonathan L. Papa, Nicholas Shkolnikov, Hatice Gulcin Ozer, Ayse Selen Yilmaz, \\ Jack C. Yalowich, and Terry S. Elton \\ Division of Pharmaceutics and Pharmacology, College of Pharmacy (E.E.K., J.C.-M., V.A.H., A.E., J.L.P., N.S., J.C.Y., T.S.E.) and \\ Department of Biomedical Informatics, College of Medicine (H.G.O., A.S.Y.), The Ohio State University, Columbus, Ohio
}

Received October 4, 2019; accepted December 6, 2019

\begin{abstract}
DNA topoisomerase $l 1 \alpha$ protein (TOP2 $\alpha) 170 \mathrm{kDa}(\mathrm{TOP} 2 \alpha / 170)$ is an important target for anticancer agents whose efficacy is often attenuated by chemoresistance. Our laboratory has characterized acquired resistance to etoposide in human leukemia K562 cells. The clonal resistant subline KNP.5 contains reduced TOP2 $\alpha / 170$ mRNA and protein levels compared with parental K562 cells. The aim of this study was to determine whether microRNA (miRNA)-mediated mechanisms play a role in drug resistance via decreased expression of TOP $2 \alpha / 170$. miRNAsequencing revealed that human miR-9-3p and miR-9-5p were among the top six of those overexpressed in KNP.5 compared with K562 cells; validation by quantitative polymerase chain reaction demonstrated overexpression of both miRNAs. miRNA recognition elements (MREs) for both miRNAs are present in the $3^{\prime}$-untranslated region (UTR) of TOP $2 \alpha / 170$. Transfecting K562 cells with a reporter plasmid harboring the TOP2 $\alpha / 1703^{\prime}$-UTR together with either miR-9-3p or miR-9-5p mimics resulted in a statistically significant decrease in luciferase expression. Mutating the miR-9-3p or miR-9-5p MREs prevented this decrease, demonstrating direct interaction between these miRNAs and TOP2 $\alpha / 170$ mRNA. Transfection of K562 cells with miR-9$3 p$ or miR-9-5p mimics led to decreased TOP $2 \alpha / 170$ protein
\end{abstract}

levels without a change in TOP $2 \alpha / 170$ mRNA and resulted in attenuated etoposide-induced DNA damage (gain-of-miRNAinhibitory function). Conversely, transfection of miR-9-3p or miR9-5p inhibitors in K/VP.5 cells (overexpressed miR-9 and low TOP $2 \alpha / 170$ ) led to increased TOP $2 \alpha / 170$ protein expression without a change in TOP2 $\alpha / 170$ mRNA levels and resulted in enhancement of etoposide-induced DNA damage (loss-ofmiRNA-inhibitory function). Taken together, these results strongly suggest that these miRNAs play a role in and are potential targets for circumvention of acquired resistance to etoposide.

\section{SIGNIFICANCE STATEMENT}

Results presented here indicate that miR-9-3p and miR-9-5p decrease DNA topoisomerase Il $\alpha$ protein $170 \mathrm{kDa}$ expression levels in acquired resistance to etoposide. These findings contribute new information about and potential strategies for circumvention of drug resistance by modulation of microRNA levels. Furthermore, increased expression of miR-9-3p and miR-9-5p in chemoresistant cancer cells may support their validation as biomarkers of responsiveness to DNA topoisomerase II-targeted therapy.

\section{Introduction}

DNA topoisomerase II $\alpha$ (TOP2 $\alpha) 170 \mathrm{kDa}$ (TOP2 $\alpha / 170)$ induces covalent complexes with DNA and produces transient double-strand DNA breaks crucial for processes such as replication and chromosomal dysjunction at mitosis (Deweese and Osheroff, 2009). The TOP2 $\alpha / 170$ enzyme exists as a homodimer. Each monomer utilizes a tyrosine active site as a nucleophile to begin a reversible transesterification reaction with

This work was supported by the National Institutes of Health National Cancer Institute [Grant R01 CA226906-01A1].

https://doi.org/10.1124/mol.119.118315. $5^{\prime}$-nucleobase scissile sites on the phosphate backbones of the top or bottom strands of DNA (Deweese and Osheroff, 2009). This cleavage and subsequent rapid religation of DNA allows for the relaxation/separation of DNA entanglements (Vos et al., 2011; Chen et al., 2013; Pendleton et al., 2014; Ashour et al., 2015). TOP $2 \alpha / 170$ has been used as an important target in cancer therapy (Larsen et al., 2003; Deweese and Osheroff, 2009; Nitiss, 2009; Pommier et al., 2010). Type IIA topoisomerase interfacial inhibitors, such as etoposide, stabilize the otherwise short-lived enzyme-DNA complexes by insertion within the four base pair scissile break sites generated by TOP2 $\alpha / 170$ (Laponogov et al., 2010; Pommier et al., 2010),

ABBREVIATIONS: ABCB1, multidrug resistance protein 1/P-glycoprotein; ADR, Adriamycin; AML, acute myeloid leukemia; EOC, epithelial ovarian carcinoma; GAPDH, glyceraldehyde 3-phosphate dehydrogenase; luc, luciferase; miRNA, microRNA; miRISC, miRNA-RISC complex; MRE, miRNA recognition element; mut, mutant; PCR, polymerase chain reaction; pre-miRNA, precursor miRNA; pri, primary; PVDF, polyvinylidene difluoride; qPCR, quantitative PCR; RISC, RNA-induced silencing complex; RUNX1, runt-related family transcription factor 1; Seq, sequencing; TBP, TATAbinding protein; TOP $2 \alpha$, DNA topoisomerase Il $\alpha$ protein; TOP $2 \alpha / 170$, TOP $2 \alpha 170 \mathrm{kDa}$; TOP $2 \alpha / 90$, TOP $2 \alpha 90$ kDa; UTR, untranslated region. 
thereby inhibiting religation. Programmed cell death can ensue because of an aggregation of double-strand DNA breaks (Pommier et al., 2010).

Acquired resistance to TOP2 $\alpha / 170$-targeted agents (e.g., etoposide, mitoxantrone, amsacrine, doxorubicin, and analogs) is important clinically in the treatment of a variety of malignancies (Chen and Liu, 1994; Vassetzky et al., 1995; Pilati et al., 2012; Ganapathi and Ganapathi, 2013). Though mutant forms of TOP2 $\alpha$ have been reported in acquired resistance (Zwelling et al., 1989; Bugg et al., 1991; Hinds et al., 1991; Kubo et al., 1996), most evidence from selected cell lines (Ritke and Yalowich, 1993; Ritke et al., 1994; Mirski et al., 1993, 2000; Harker et al., 1995; Mirski and Cole, 1995; Wessel et al., 1997; Yu et al., 1997; Burgess et al., 2008) and patient samples (Ganapathi and Ganapathi, 2013) suggests that decreased levels of TOP2 $\alpha$ are a major determinant of drug resistance. Our laboratory has previously demonstrated that a cloned K562 cell line (designated K/VP.5 cells) with acquired resistance ( 25 -fold) to etoposide expresses less TOP2 $\alpha / 170$ protein compared with the parental K562 cells with no change in drug accumulation and no overexpression of multidrug resistance protein 1/P-glycoprotein (ABCB1) (Ritke and Yalowich, 1993; Ritke et al., 1994). In addition, K/VP.5 cells overexpressed a novel TOP2 $\alpha 90 \mathrm{kDa}$ (TOP2 $\alpha / 90$ ) isoform, the translation product of TOP $2 \alpha$ mRNA that retains a processed intron 19 (Kanagasabai et al., 2017; Kanagasabai et al., 2018). Importantly, the TOP $2 \alpha / 90$ isoform heterodimerizes with the TOP $2 \alpha / 170$ isoform, resulting in a dominantnegative effect with respect to etoposide-induced covalent TOP2 $\alpha$-DNA complexes, DNA damage, and cytotoxicity (Kanagasabai et al., 2018). Together, literature indicates that acquired resistance to TOP $2 \alpha$-targeted agents can result from multiple mechanisms involving dysregulation of TOP $2 \alpha$.

MicroRNA (miRNA)-mediated post-transcriptional gene silencing is an established mechanism of genetic regulation (Bartel, 2009). Typically, mature noncoding miRNAs (21-25 nucleotides) are embedded in primary (pri)-miRNA transcripts as imperfectly based-paired stem-loops (Ha and $\mathrm{Kim}, 2014)$. In the nucleus, pri-miRNA is further processed to a hairpin-structured precursor miRNA (pre-miRNA) of $\sim 60-70$ nucleotides. Subsequently, in the cytoplasm, the terminal loop is removed, the resulting miRNA duplexes of $\sim 22$ nucleotides are loaded into the RNA-induced silencing complex (RISC), and then the duplex is matured (Treiber et al., 2019). Importantly, two distinct functional mature miRNAs can be processed from opposite sides of the same pre-miRNA (i.e., miRNA matured from the $5^{\prime}$ arm denoted $-5 \mathrm{p}$ or from the $3^{\prime}$ arm denoted $-3 p$ ) (Treiber et al., 2019). Finally, the miRNA-RISC complex (miRISC) is guided by a seed sequence (spanning position $2-8$ at the $5^{\prime}$ end of the miRNA) that base pairs to a specific miRNA recognition element (MRE) typically harbored in the 3 '-untranslated region (UTR) of a target mRNA (Bushati and Cohen, 2007). Interactions of miRNAs with the $5^{\prime}$-UTR and coding region of mRNAs have also been reported (Broughton et al., 2016). Upon mRNA binding, miRISC will reduce the expression of the target mRNA by blocking the ribosome from mRNA translation and/ or by initiating mRNA degradation (Fabian and Sonenberg, 2012; Jonas and Izaurralde, 2015).

In this study, we posit that TOP $2 \alpha / 170$ expression is attenuated in etoposide-resistant K/VP.5 cells, in part by miRNA-mediated mechanisms that are determinants of drug resistance. Results demonstrated that human miR-9-3p (previously denoted miR-9*) and miR-9-5p (previously denoted miR-9): 1) were overexpressed in K/VP.5 cells; 2) contained corresponding MREs in the 3 -UTR of TOP $2 \alpha / 170$; 3 ) functionally regulated the protein expression levels of TOP $2 \alpha / 170$; and 4) modulated etoposide activity. Altogether results are consistent with a role for these miRNAs in acquired drug resistance.

\section{Materials and Methods}

Cell Culture. Human K562 leukemia cells were maintained in Dulbecco's modified Eagle's medium (Corning, Manassas, VA) supplemented with $10 \%$ FBS. Cloned etoposide-resistant K562 cells (K/VP.5) were generated by continuous incubation in $0.5 \mu \mathrm{M}$ etoposide followed by isolation via limiting dilution, as previously described (Ritke and Yalowich, 1993). K/VP.5 cells were maintained in Dulbecco's modified Eagle's medium $/ 10 \%$ FBS with $0.5 \mu \mathrm{M}$ etoposide added every other week. All experiments described below were performed utilizing K562 and K/VP.5 cells growing in log phase.

miRNA-Sequencing. A mirVana miRNA Isolation Kit with phenol was used to isolate total RNA from K562 and K/VP.5 cells following the manufacturer's recommended instructions (cat. no. AM1560; ThermoFisher, Waltham). The total RNA was subsequently DNase I-treated and concentrated on a spin-column following the manufacturer's recommended instructions (cat. no. R1013; Zymo Research, Irvine, CA). miRNA-sequencing (Seq) analysis was performed by the Biomedical Genomics Core of The Research Institute at Nationwide Children's Hospital, Columbus, OH. Briefly, NEB Next Small RNA libraries were prepared from the purified K562 and K/VP.5 total RNA samples and the libraries were size selected using Sage Pippin (130-200 bp range, adapters are $\sim 128 \mathrm{bp}$ ) with an average final library size of $180 \mathrm{bp}$ and sequenced on MiniSeq as $2 \times 75 \mathrm{bp}$ reads.

Computational Processing of smRNA-Seq Data. First, 3' adaptor sequences and low-quality bases were trimmed from 75 base pair paired-end sequence reads using Cutadapt v2.4 (Martin, 2011). Trimmed reads with a sequence length between 15 and 50 base pairs were aligned to potential contaminant sequences of human genome (ribosomal RNAs and transfer RNAs) using Bowtie v1.1.2 (Langmead et al., 2009) with a seed length of 18 and allowing zero mismatches in the seed. Then, remaining reads were aligned to miRBase (GriffithsJones, 2004) v21 mature sequences using Bowtie v1.1.2 with a seed length of 18, allowing one mismatch in seed and reporting maximum five alignments per read. Finally, remaining reads were aligned to human reference genome, Genome Reference Consortium human genome build 38, using Bowtie v1.1.2 with a seed length of 18 , allowing one mismatch in seed and reporting only unique alignments for each read. Using Samtools (Li et al., 2009) and in-house R scripts, total number of reads for each mature miRNA was counted. Fractional counts were used when a sequence read aligned to more than one miRNA. Genomic alignment was quantified using featureCounts function of SubReads (Liao et al., 2014) with Gencode v22 annotation. Using limma R/Biconductor package (Ritchie et al., 2015), raw read counts were normalized as log2 counts per million, and differential expression analysis was performed between three K562 and four K/VP.5 RNA samples.

TOP2 $\alpha / 170$ mRNA/miRNA Bioinformatic Analyses. To predict putative MREs harbored in the $3^{\prime}$-UTR of TOP $2 \alpha / 170$ mRNAs, multiple computational algorithms were used (TargetScan 7.2, http:// www.targetscan.org; Agarwal et al., 2015 and DIANA-microT-CDS, $\mathrm{http} / / / \mathrm{www}$.microrna.gr/microT-CDS, fifth version of the microT algorithm, Paraskevopoulou et al., 2013). GEO accession number for small (sm)RNA-seq data: GSE141687.

Luciferase Reporter Constructs. The psiCHECK-2 dual luciferase vector was purchased from Promega Corporation (cat. no. C8021; Madison, WI) and linearized by XhoI digestion (cat. no. R0146S; New England Biolabs, Ipswich, MA) according to the manufacturer's protocol. 
A 998-bp fragment encompassing the entire TOP2 $\alpha / 1703^{\prime}$-UTR was polymerase chain reaction (PCR)-amplified by utilizing sense ( $5^{\prime}$-AGG CGATCGCTCGAGAATGTGAGGCGATTATTTTAAGTAA- ${ }^{\prime}$ ) and antisense (5'-ATTCCCGGGCTCGAGTGGGTTGCAATGTTT AGAACATT-3') primers using standard PCR procedures with a proofreading polymerase, CloneAmp HiFi (cat. no. 639298; Takara Bio Inc., Kusatsu, Shiga, Japan). Genomic DNA isolated from K562 cells was used as template. The primer sequences homologous to the regions immediately downstream of the TOP $2 \alpha / 170$ stop codon and immediately upstream of the TOP $2 \alpha / 170$ poly(A) tail are bolded above. The sense and antisense primers also harbor 15 nucleotide extensions (not bolded) that are homologous to ends of the XhoI linearized dual luciferase psiCHECK-2 reporter plasmid and are necessary for "InFusion" cloning methodology (In-Fusion HD Cloning Kit, cat. no. 638916; Takara Bio Inc). The TOP $2 \alpha / 170$ 3'-UTR PCR product was gel purified and subcloned into the XhoI site, which is located downstream of the Renilla luciferase (luc) reporter open reading frame in the psiCHECK-2 reporter plasmid, utilizing the manufacturer's protocol. The authenticity and orientation of the inserts relative to the Renilla luciferase gene were confirmed by dideoxy sequencing. The resulting recombinant plasmid was designated psiTOP $2 \alpha / 170 / \mathrm{UTR}$.

The mutant reporter construct psiTOP $2 \alpha / 170 / \mathrm{UTR}$-mutant (mut)$5 \mathrm{p}$ was generated utilizing the psiTOP $2 \alpha / 170 / \mathrm{UTR}$ vector as template and mutating the miR-9-5p MRE (located at 703-709 bp) harbored in the TOP2 $\alpha / 1703$ '-UTR using a Q5 Site-Directed Mutagenesis kit from New England Biolabs (cat. no. E0554S) following the manufacturer's instructions. The primers used for mutagenesis were sense (5'-AAG CGTGGAGAAACCAATTTCTAAG- ${ }^{\prime}$ ) and antisense (5'-GAGATTCA GACTCAGAGGCAGC-3'). Importantly, these primers were designed with their $5^{\prime}$ ends annealing back-to-back (inverse PCR). The nucleotides that were mutated are shown in bold print. The mutation of the miR-9-5p seed sequence was confirmed by dideoxy sequencing. The mutant reporter construct psiTOP $2 \alpha / 170 /$ UTR-mut-3p was generated in the same manner as psiTOP $2 \alpha / 170 /$ UTR-mut-5p but the predicted miR-9-3p site was modified (466-471 bp of the $3^{\prime}$-UTR) with the following sense (5'-GAAACTGGTTCTAGTACAGATAC- $\left.3^{\prime}\right)$ and antisense ( $5^{\prime}$-TTCTATCTGATGGTAAA-TTATG-3') primers. Finally, transformed bacterial cultures were grown, and each reporter construct was isolated with a Qiagen Plasmid Midi Kit (cat. no. 12143; Hilden, Germany).

Transfection Experiments. K562 and K/VP.5 cells $\left(5 \times 10^{5}\right.$ in $5 \mathrm{ml}$ per condition) were transfected with the psiTOP $2 \alpha / 170 / \mathrm{UTR}$ dual luciferase construct utilizing $1 \mu \mathrm{g}$ of the plasmid, $5.5 \mu \mathrm{l}$ Lipofectamine 3000, $10 \mu \mathrm{l}$ P3000 (cat. no. L3000008; ThermoFisher), and $250 \mu \mathrm{l} \mathrm{Opti-}$ Mem Medium (cat. no. 31985062; ThermoFisher). Cotransfection experiments utilizing K562 cells were performed as described above with the respective dual luciferase construct (psiTOP2 $\alpha / 170 /$ UTR, psiTOP2 $\alpha / 170 /$ UTR-3p-mut, or psiTOP2 $\alpha / 170 /$ UTR-5p-mut) and either a miRNA mimic negative control (cat. no. 4464058; ThermoFisher), miR-9-3p mimic (cat. no. MC13072), or miR-9-5p mimic (cat. no. MC10022). In addition, K562 cells were transfected with only the mimics described above for subsequent TOP $2 \alpha / 170$ immuno-assays and for DNA damage studies. Finally, K/VP.5 cells were transfected with either a miRNA inhibitor negative control (cat. no. MH4464076; ThermoFisher), miR-9-3p inhibitor (cat. no. MH13072), or miR-9-5p inhibitor (cat. no. MH10022). In all transfection experiments employing miRNA mimics or miRNA inhibitors, the final concentration was $25 \mathrm{nM}$. Forty-eight hours after transfection, total RNA and/or cellular extracts were prepared for quantitative PCR (qPCR), luciferase, immunoblotting, and DNA damage assays as outlined below.

Quantitative PCR Assays. Total RNA was isolated from nontransfected and transfected K562 and K/VP.5 cells using PureZOL RNA Isolation Reagent from Bio-Rad Laboratories (cat. no. 7326880; Hercules, CA). RNA samples were subsequently treated with DNase I (TURBO DNA-free Kit, cat. no. AM2238; ThermoFisher Scientific). RNA $(1 \mu \mathrm{g})$ used for TOP2 $\alpha / 170$ mRNA quantification experiments was reverse transcribed using random hexamers and MultiScribe
Reverse Transcriptase (High Capacity cDNA Reverse Transcription Kit, cat. no. 4368814; ThermoFisher Scientific) as previously described by our laboratory (Kanagasabai et al., 2017, 2018). qPCR evaluations $(20 \mu \mathrm{l} /$ reaction) were performed using $5 \mu \mathrm{l}$ of a 1:10 dilution of cDNA with primer/probe sets specific for TOP2 $\alpha / 170$ (Assay ID Hs01032135_m1; ThermoFisher Scientific) and TATA-binding protein (TBP) (Assay ID Hs99999910_ml; ThermoFisher Scientific). The relative gene expression level of TOP $2 \alpha / 170$ in each experimental condition was normalized to TBP expression using the $2^{-\Delta \Delta \mathrm{Ct}}$ method (Schmittgen and Livak, 2008). In addition, RNA samples (50 ng) were reverse transcribed using miR-9-3p, miR-9-5p, and RNU48 antisense primers and MultiScribe Reverse Transcriptase in a $15 \mu \mathrm{l}$ reaction according to manufacturer instructions. qPCR for miRNA quantification ( $20 \mu \mathrm{l} /$ reaction) was performed using $1.33 \mu \mathrm{l}$ of cDNA with primer/probe sets specific for miR-9-3p (Assay ID 00231), miR-9-5p (Assay ID 000583), and RNU48 (Assay ID 001006). The relative gene expression level of miR-9-3p and/or miR-9-5p in each experimental condition was normalized to RNU48 expression using the $2^{-\Delta \Delta \mathrm{Ct}}$ method (Schmittgen and Livak, 2008). Finally, cDNA synthesized from RNA isolated from nontransfected K562 and K/VP.5 cells was used in qPCR experiments with primer/probe sets specific for pri hsa-miRNA-9s (mir-9-1, Assay ID Hs03303201_pri; mir-9-2, Assay ID Hs03303202_pri; and mir-9-3, Assay ID Hs03293595_pri; ThermoFisher Scientific). The relative gene expression level of mir-9-1, mir-9-2, and mir-9-3 in K562 and $\mathrm{K} / \mathrm{VP} .5$ cells was normalized to TBP expression using the $2^{-\Delta \Delta \mathrm{Ct}}$ method (Schmittgen and Livak, 2008).

Luciferase Assay. Forty-eight hours after transfection, K562 and/or K/VP.5 cells were washed and lysed with passive lysis buffer (cat. no. E1941; Promega), and firefly and Renilla luciferase activities were determined by using the Dual-Luciferase Reporter Assay System (cat. no. E1910; Promega) with a Synergy H1 Hybrid Multi-Mode Reader (BioTek, Winooski, VT). Renilla luciferase expression in the psiCHECK-2 vector is generated via an SV40 promoter, whereas firefly luciferase in this vector is generated via a herpes simplex virus1 thymidine kinase promoter and has been specifically designed to be an intraplasmid transfection normalization reporter. The Renilla luciferase signal was therefore normalized to the firefly luciferase signal.

Western Blot Analysis. Forty-eight hours after transfection, K562 and/or K/VP.5 cells were pelleted and washed in PBS. After washing, 1.5 million cells were lysed in $2 \times$ Laemmli sample buffer (cat. no. 1610737; Bio-Rad Laboratories) containing $5 \% \beta$-mercaptoethanol and boiled at $100^{\circ} \mathrm{C}$ for 5 minutes. DNA was sheared using a sonicator (Tekmar, Mason, $\mathrm{OH}$ ) at $35 \mathrm{~W}$ three times in 10-second intervals, and the samples were subsequently electrophoresed on a NuPAGE 4\%-12\% [bis(2hydroxyethyl)amino]-2-(hydroxymethyl)propane-1,3-diol gel (cat. no. NP0322BOX; ThermoFisher). Duplicate samples were run with an equal amount of protein $(16.6 \mu \mathrm{g})$ loaded into each well, and an equal volume of Precision Plus Protein Dual Color Standards was also run for molecular weight reference (cat. no. 1610374; Bio-Rad Laboratories). Protein was transferred to a polyvinylidene difluoride (PVDF) membrane (cat. no. 1620177; Bio-Rad Laboratories) using a semidry electroblotter (ThermoFisher). The PVDF membrane was then sectioned. The $75-250 \mathrm{kDa}$ portion was labeled by overnight incubation at $4^{\circ} \mathrm{C}$ with rabbit polyclonal antibodies raised against the $\mathrm{N}$-terminal sequence of human TOP2 $\alpha / 170$ (cat. no. ab74715; Abcam, Cambridge, MA; used at 1:1000 dilution). The $25-75 \mathrm{kDa}$ portion was labeled by overnight incubation at $4^{\circ} \mathrm{C}$ with a [glyceraldehyde 3phosphate dehydrogenase (GAPDH)] mouse monoclonal antibody (1: 5000; cat. no. sc-47724; Santa Cruz Biotechnology, Santa Cruz, CA). PVDF membranes were subsequently incubated at room temperature for 1.5 hours with a donkey anti-rabbit or donkey anti-mouse secondary antibody, respectively (1:8000 dilution; Jackson ImmunoResearch, West Grove, PA). Antibody-labeled TOP $2 \alpha / 170$ and GAPDH were detected using the Immun-Star horseradish peroxidase Chemiluminescence Kit (cat. no. 170-5040; Bio-Rad Laboratories). All immunoassay images were taken with the ChemiDoc 
XRS+ imaging system and analyzed with ImageLab software (BioRad Laboratories).

Comet DNA Damage Assays. Single-cell gel electrophoresis (Comet) assays were performed according to the manufacturer's protocol (cat. no. 4250-050-K; Trevigen, Gaithersburg, MD) and as previously described by our laboratory (Vlasova et al., 2011; Kanagasabai et al., 2017). Briefly, K562 or K/VP.5 cells were transfected with miR-9 mimics or inhibitors, respectively, as described above. Forty-eight hours after transfection, cells were washed and resuspended in buffer (25 mM HEPES, $10 \mathrm{mM}$ glucose, $1 \mathrm{mM} \mathrm{MgCl}_{2}, 5 \mathrm{mM} \mathrm{KCl}, 130 \mathrm{mM} \mathrm{NaCl}, 5 \mathrm{mM}$ monosodium phosphate, $\mathrm{pH}$ 7.4). Transfected K562 cells were subsequently incubated with 2 or $5 \mu \mathrm{M}$ etoposide or DMSO (solvent control) for 1 hour at $37^{\circ} \mathrm{C}$. Transfected K/VP.5 cells were incubated with 10 or $25 \mu \mathrm{M}$ etoposide or DMSO for 1 hour at $37^{\circ} \mathrm{C}$. Cells were subsequently washed with ice-cold buffer and resuspended to $0.28 \times$ $10^{6}$ cells $/ \mathrm{ml}$ and then diluted so that $\sim 2000$ cells in low melt agarose underwent alkaline electrophoresis. After staining with a fluorescent DNA intercalating dye, SYBR Gold, the migrating fragments (comet tail) from the nucleoid (comet head) were visualized and the images captured by fluorescence microscopy. The Olive tail moment, which is defined as the product of the comet tail length and the fraction of total DNA in the comet tail (Olive, 2002 ), was quantified by the ImageJ processing program with the open-source software tool Open Comet (Gyori et al., 2014). Olive tail moments from greater than 100 cells per sample condition were determined.

Data Analysis. Statistical analysis was performed using SigmaPlot 14. All data are expressed as the mean \pm S.D. Group-wise differences were analyzed using a two-tailed paired Student's $t$ test with no correction for multiple comparisons. qPCR gene expression data $\left(2^{-\Delta \mathrm{Ct}}\right.$ values) were subjected to $\log$ transformation to assure distribution normality prior to paired Student's $t$ test analysis (Ganger et al., 2017). A $P$ value of $<0.05$ was considered statistically significant.

\section{Results}

TOP2 $\alpha / 170$ Expression Is Attenuated in EtoposideResistant K562 Cells. Our laboratory previously established and characterized an etoposide-resistant K562 cell line, designated K/VP.5 cells (Ritke and Yalowich, 1993), which are cross-resistant also to other TOP2 $\alpha / 170$-targeted agents (Ritke et al., 1994). To demonstrate resistance to etoposide, cell growth inhibition of K562 and K/VP.5 cells was evaluated by 48-hour incubation with increasing concentrations of etoposide. Results show that K/VP.5 cells are 26 -fold resistant to etoposide (Fig. 1A). To investigate the relative TOP2 $\alpha / 170$ mRNA expression levels, K562 and K/VP.5 cDNAs were subjected to qPCR utilizing TaqMan hydrolysis primers/probes. The results of these experiments demonstrated that TOP $2 \alpha / 170$ mRNA expression levels were reduced in K/VP.5 cells to $41.2 \%$ the level expressed in parental K562 cells (Fig. 1B), recapitulating the 2.5 -fold reduction of TOP $2 \alpha / 170$ mRNA in K/VP. 5 cells found previously by Northern blot analysis (Ritke and Yalowich, 1993). TOP2 $\alpha / 170$ protein expression was also decreased in K/VP.5 cells to a level $10.6 \%$ that of parental K562 cells (Fig. 1C).

miR-9-3p and miR-9-5p Are Overexpressed in K/VP.5 Cells. Because miRNAs play an integral role in almost all known biologic processes (reviewed in Bushati and Cohen,
A

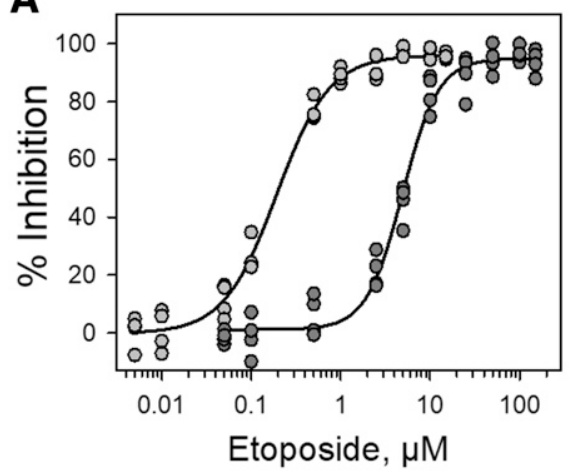

B

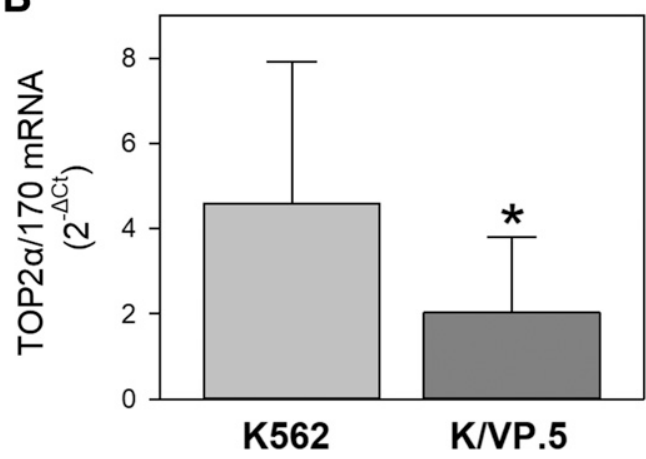

C

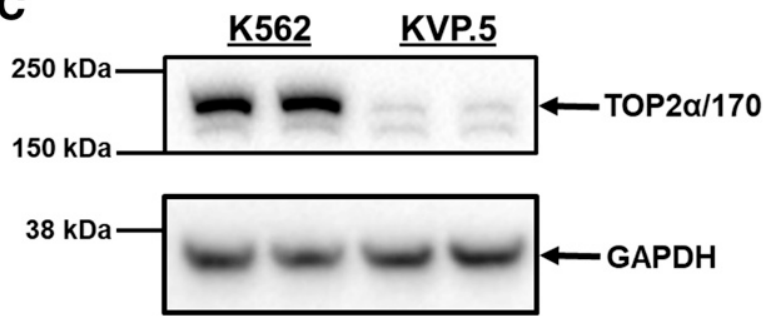

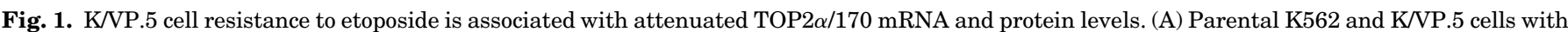

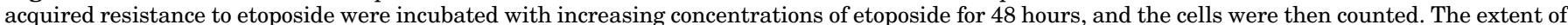

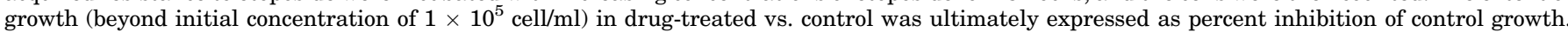

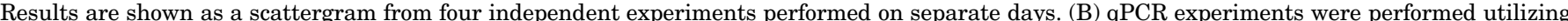

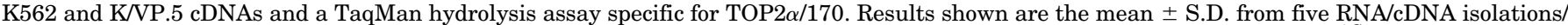

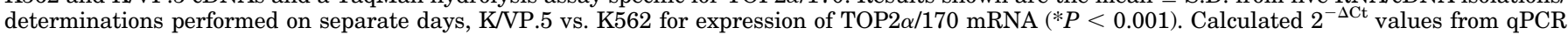

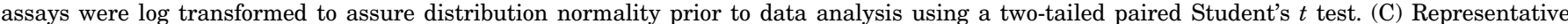

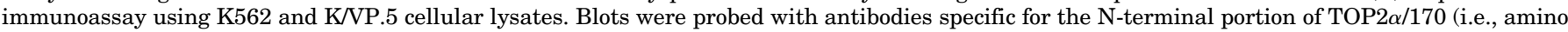

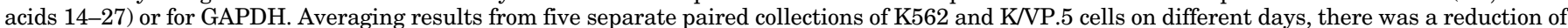
TOP $2 \alpha / 170$ in K/VP.5 cells to $10.6 \%$ the level found in parental K562 cells, taking into account the GAPDH loading control $(P=0.014)$. 
2007; Bartel, 2009; Fabian and Sonenberg, 2012), we hypothesized that TOP2 $\alpha / 170$ expression is attenuated in K/VP.5 cells, in part by a miRNA-mediated mechanism. As an initial test of this hypothesis, total mRNA was isolated from K562 and K/VP.5 cells, and small RNA libraries were generated, size selected, and sequenced to examine the global miRNA expression levels in both cell lines. The volcano plot (Fig. 2A) illustrates that, of the $\sim 300$ mature miRNAs that were detected in these cells, 73 miRNAs were overexpressed (fold change $>2$; adjusted $P$ value $<0.05$ ) and 14 were underexpressed (fold change $>2$; adjusted $P$ value $<0.05$ ) in K/VP.5 compared with K562 cells.

The miRNA-Seq data demonstrated that miR-9-3p (75.1fold) and miR-9-5p (26.2-fold) were among the top six overexpressed pre-miRNAs in K/VP.5 cells (Fig. 2A). TargetScan (Agarwal et al., 2015) and DIANA-microT-CDS (Paraskevopoulou et al., 2013) algorithms identified a putative mature miR-9-5p MRE located at position 703-709 nt in the TOP2 $\alpha / 1703^{\prime}-\mathrm{UTR}$ (Fig. 2B). In addition, a putative seed sequence for miR-9-3p binding was also predicted - by DIANA-microT-CDS at position $466-471 \mathrm{nt}$ of the TOP2 $\alpha / 1703^{\prime}$-UTR (Fig. 2B). Based on these evaluations and literature establishing that miR-9-3p and miR-9-5p can be simultaneously matured from pre-miR (mir-9) (Packer et al., 2008; Schraivogel et al., 2011, Nowek et al., 2016, 2018), the potential effects of both these miRNAs were studied further.

To independently validate the miR-9 miRNA-Seq data (Fig. 2A), qPCR experiments were performed utilizing TaqMan primer/probe sets specific for mature miR-9-3p and miR-9-5p. Both miR-9-3p and miR-9-5p were statistically significantly overexpressed in K/VP.5 cells compared with K562 cells: 18.6fold and 12.7-fold, respectively; $P<0.001$ (Fig. 2C). Because miR-9-3p and miR-9-5p can be matured from pri-miRNAs (mir-9s) transcribed from three independent genes, with MIR9-1, MIR9-2, and MIR9-3 located on chromosomes 1, 5, and 15, respectively (Yuva-Aydemir et al., 2011), qPCR experiments were performed utilizing TaqMan primer/probe sets specific for each MIR9 gene. These experiments demonstrated that mir-9-1 was the only miRNA precursor statistically significantly overexpressed in K/VP.5 cells compared with K562 cells (18.6-fold; $P<0.001$ ) (Fig. 2D). Together, these observations suggest that it is the activation of the
A
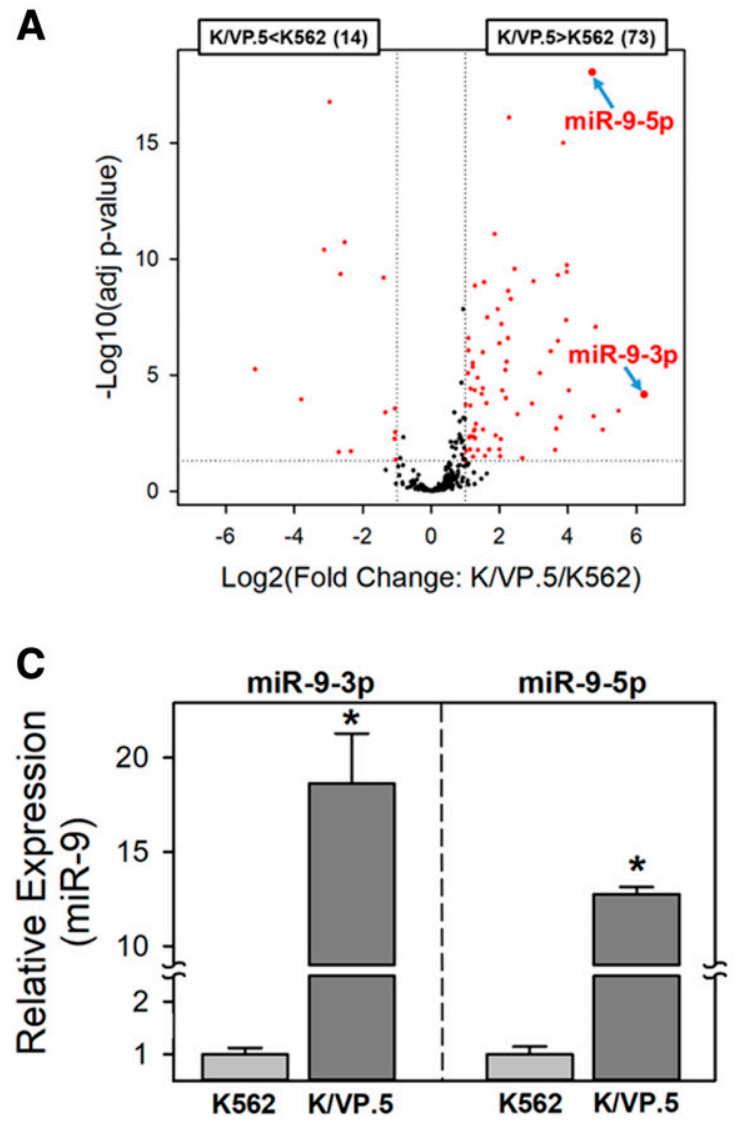

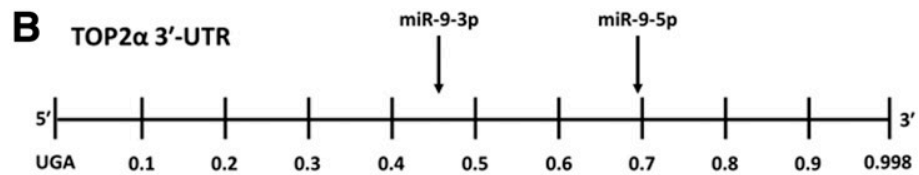

Position 456-471 $\rightarrow 5^{\prime}$.... UACCAUCAGAUAGAACUUUAU...3' of TOP2 $\alpha$ 3'UTR ||||| hsa-miR-9-3p $\longrightarrow$ 3'..UGAAAGCCAAUAGAUCGAAAUA...5'

Position 688-710 $\rightarrow$ 5'....CUGAGUCUGAAUCUCCCAAAGA...3' of TOP2 $\alpha$ 3'UTR

hsa-miR-9-5p $\longrightarrow$ 3'..AGUAUGUCGAUCUAUUGGUUUCU..5'

D

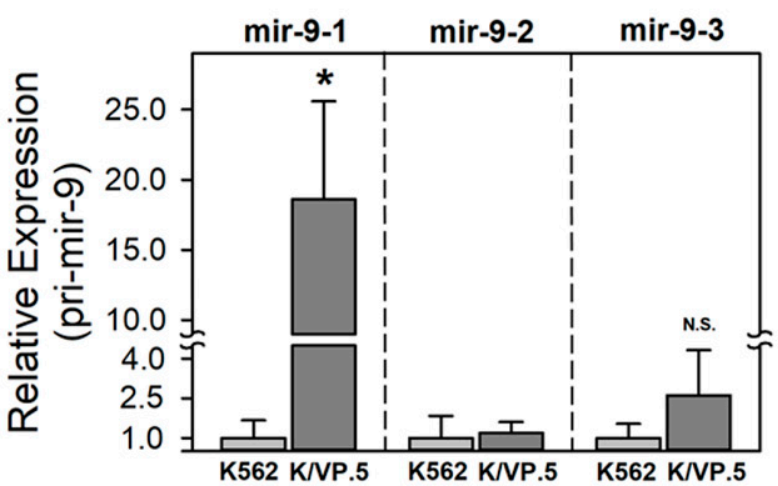

Fig. 2. miR-9-3p and miR-9-5p are overexpressed in K/VP.5 cells. (A) Volcano plot analysis of miRNAs overexpressed or underexpressed in K/VP.5 compared with K562 cells. Differentially expressed miRNAs are defined as those with at least a \pm 2 -fold change [red circles outside vertical dotted lines and above the horizontal dotted line $(P<0.05)$ ]. (B) Schematic representation of the location of putative MREs harbored in the 3 '-UTR of TOP2 $\alpha / 170$ mRNA. Additionally, the "seed sequence" complementarity is shown between miR-9-3p and miR-9-5p and the putative TOP2 $\alpha / 170$ 3'-UTR MREs. (C) qPCR utilizing K562 and K/VP.5 cDNAs and TaqMan hydrolysis assays specific for miR-9-3p and miR-9-5p. Results shown are the mean \pm S.D. for three determinations made from three separate RNA/cDNA preparations made on separate days; ${ }^{*} P<0.001$, comparing K/VP.5 to K562 cell levels of miR-9-3p and miR-9-5p. (D) qPCR utilizing K562 and K/VP.5 cDNAs and TaqMan hydrolysis assays specific for pri-miRNAs (i.e., mir-9-1, mir-9-2, and mir-9-3) transcribed from three independent genes: MIR9-1, MIR9-2, and MIR9-3. Results shown are the mean \pm S.D. from four to seven determinations made from separate RNA/cDNA preparations; $* P<0.001(N=7)$, comparing K/VP.5 to K562 cell levels of mir-9-1; $* P=0.078(N=4)$, comparing K/VP.5 to K562 cell levels of mir-9-3. For Fig. 2, C and D, calculated $2^{-\Delta \mathrm{Ct}}$ values from qPCR assays were log transformed to assure distribution normality prior to data analysis using a two-tailed paired Student's $t$ test. N.S., not significant. 
MIR9-1 gene that results in the overexpression of miR-9-3p and miR-9-5p in K/VP.5 cells.

miR-9-3p and miR-9-5p Directly Interact with the TOP2 $\alpha / 170$ 3'-UTR. Initial evaluation of putative miRNA regulation of TOP $2 \alpha / 70$ expression used a dual luciferase reporter assay system in which binding of a given miRNA to its distinct MRE may repress reporter protein production, thereby reducing Renilla-luc activity (Kuhn et al., 2008; Sansom et al., 2010; Elton and Yalowich 2015). Therefore, the TOP2 $\alpha / 170$ 3'-UTR (998-bp), which harbored MREs for miR-9-3p and miR-9-5p (Fig. 2B), was subcloned immediately downstream of the Renilla-luc open reading frame, and the plasmid construct was designated psiTOP $2 \alpha / 170 /$ UTR. After transfection of cells with psiTOP $2 \alpha / 170 / \mathrm{UTR}$, there was a statistically significant reduction in luciferase activity in K/VP.5 compared with K562 cells $(P<0.001)$, suggesting a miRNA-mediated mechanism regulating TOP2 $\alpha / 170$ protein expression levels (Fig. 3A).

To evaluate the putative role of miR-9-3p and/or miR-9-5p in this regulation, K562 cells, which express low levels of miR-9$3 p$ and miR-9-5p, were cotransfected with the psiTOP2 $\alpha / 170 /$ UTR construct $(1 \mu \mathrm{g})$ plus $25 \mathrm{nM}$ miR-9-3p, miR-9-5p, or control nontargeting miRNA mimics (chemically modified double-stranded RNAs that mimic endogenous miRNAs) for
A

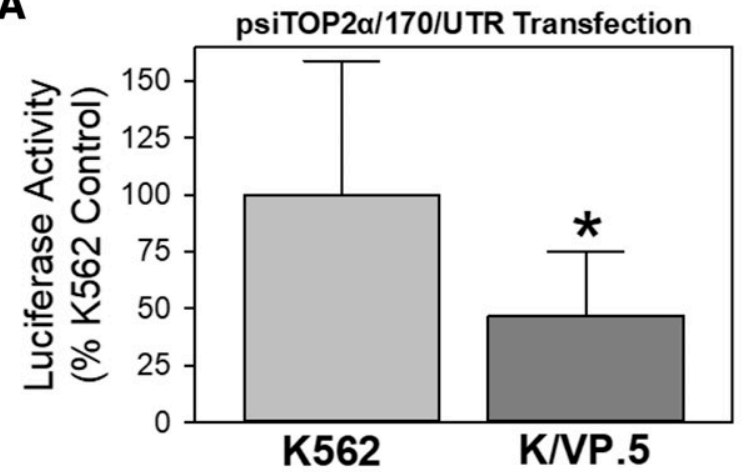

C

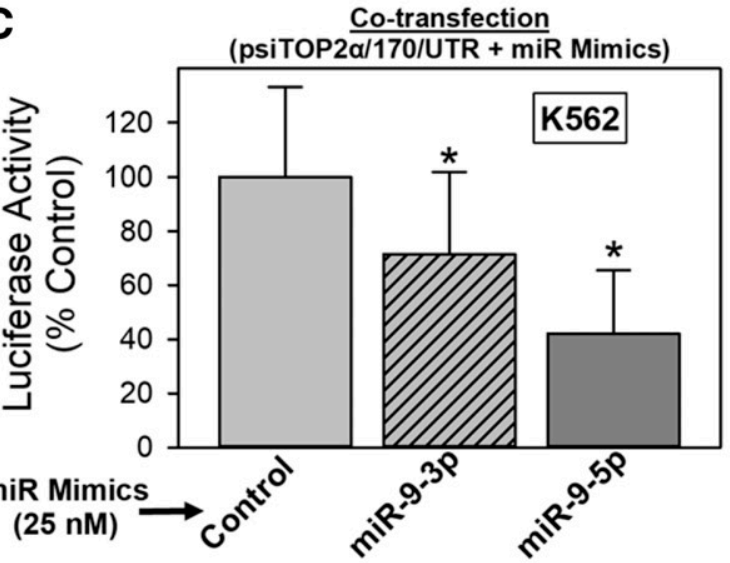

B

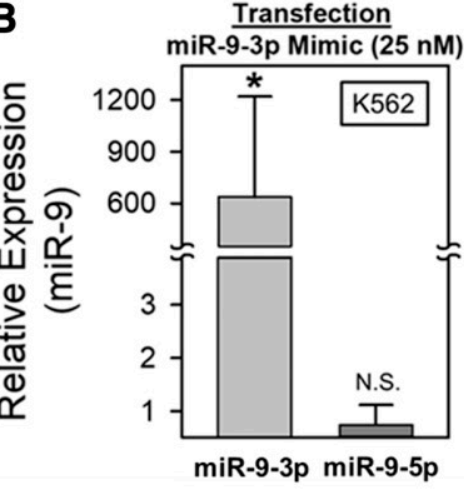

D
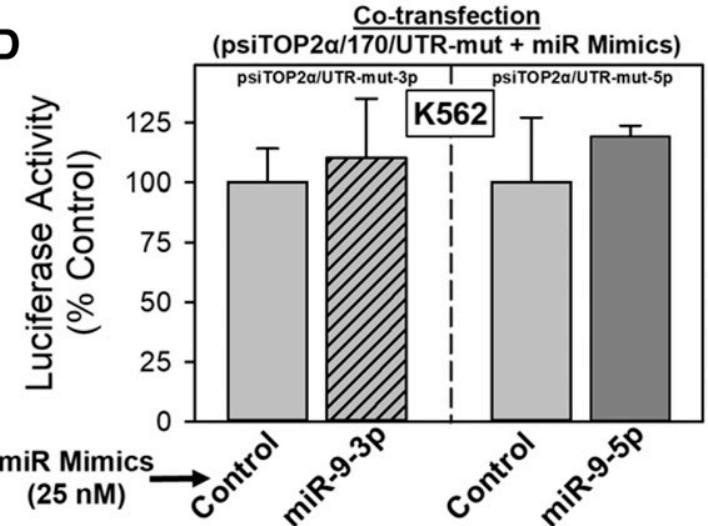

miR-9-3p MRE Mutated (psiTOP2a/UTR-mut-3p)

miR-9-5p MRE Mutated (psiTOP2 $\alpha /$ UTR-mut-5p)

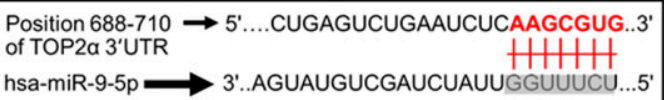

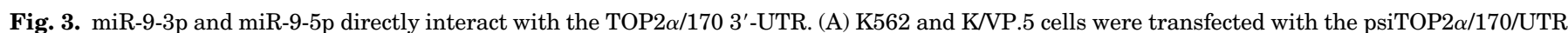

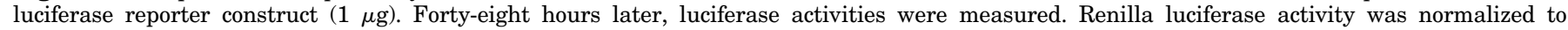

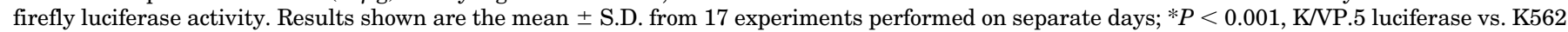

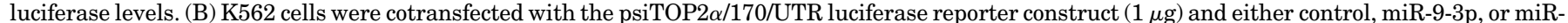

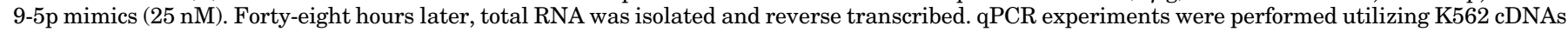

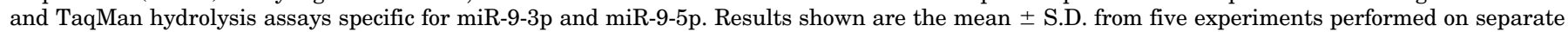

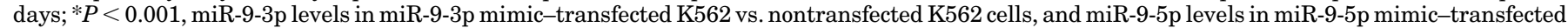

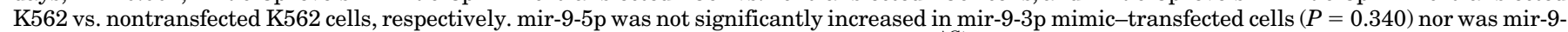

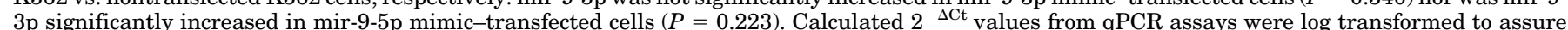

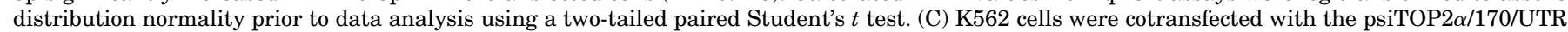

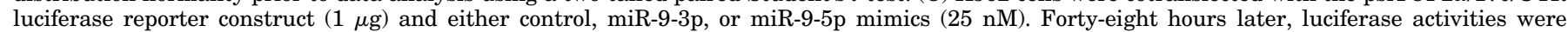

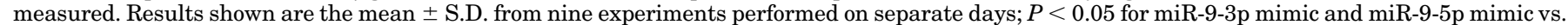

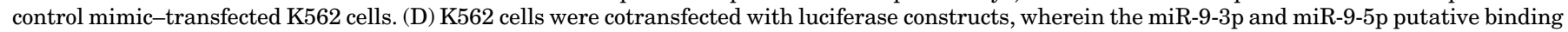

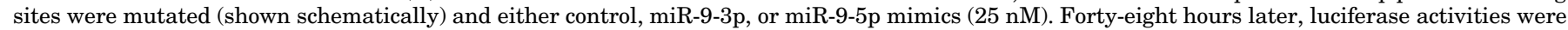
measured. Results shown are the mean \pm S.D. from three to five experiments performed on separate days. N.S., not significant. 
gain-of-inhibitory-function experiments. Forty-eight hours after transfection, qPCR experiments utilizing TaqMan probes specific for miR-9-3p or miR-9-5p demonstrated that transfection with the corresponding miRNA mimic significantly increased the detectable levels of miR-9-3p (600-fold) and miR-9-5p (94-fold), with $P<0.001$ for both (Fig. 3B). No significant increase was observed for miR-9-5p after miR-9-3p mimic transfection nor was there a statistically significant increase in miR-9-3p after mir-9-5p mimic transfection, with $P>0.220$ for both (Fig. 3B), demonstrating the specificity of miR-9 mimics and the qPCR assays. K562 cells were cotransfected with psiTOP $2 \alpha / 170 /$ UTR and miR-9 mimics, and this was followed by measurement of luciferase activity 48 hours later (Fig. 3C). There was a statistically significant reduction in luciferase activity to $71.4 \%(P=0.033)$ and $42.1 \%$ $(P=0.001)$ of the nontargeted miR-9 mimic control in cells treated with miR-9-3p mimic and miR-9-5p mimic, respectively (Fig. 3C).

To validate that miR-9-3p and miR-9-5p interact with the predicted MREs harbored in the $3^{\prime}$-UTR of TOP $2 \alpha / 170 \mathrm{mRNA}$, additional luciferase reporter constructs were generated wherein the MRE "seed" sequences (CUUUAU for miR-9-3p and CCAAAGA for miR-9-5p), which are complementary to the $5^{\prime}$ ends of miR-9-3p and miR-9-5p, were mutated (GAAACU for miR-9-3p and AAGCGUG for miR-9-5p) (Fig. 3D bottom). The mutant constructs were designated psiTOP $2 \alpha / 170 /$ UTR-mut$3 p$ and psiTOP2 $\alpha / 170 /$ UTR-mut-5p. Cotransfection of K562 cells (48 hours) with psiTOP $2 \alpha / 170 /$ UTR-mut-3p plus miR-9$3 p$ mimic or with psiTOP2 $\alpha / 170 /$ UTR-mut-5p plus miR-9-5p mimic revealed that, compared with wild-type psiTOP $2 \alpha / 170 /$ UTR transfection results (Fig. 3C), these miRNAs no longer had any effect on luciferase activity (Fig. 3D). Together, results from Fig. 3, C and D indicate that miR-9-3p and miR-9-5p can interfere with luciferase expression by directly interacting with the predicted miR-9-3p and miR-9-5p MREs harbored within the $3^{\prime}$-UTR TOP $2 \alpha / 170$ mRNA.

miR-9-3p and miR-9-5p Overexpression Results in Decreased TOP2 $\alpha / 170$ Protein and Reduced Etoposide-Induced DNA Damage in $\mathrm{K562}$ Cells. If TOP2 $\alpha / 170$ mRNA is a biologic target of miR-9-3p and miR9-5p, alteration of the endogenous expression levels of these miRNAs should correspond to predictable changes in TOP2 $\alpha /$ 170 protein. Therefore, additional gain-of-inhibitory-function experiments were performed by transfecting K562 cells (48 hours) with $25 \mathrm{nM}$ miR-9-3p, miR-9-5p, or control (nontargeting) miRNA mimics, which was followed by immunoblotting of cell lysates to evaluate TOP $2 \alpha / 170$ protein levels. Figure $4 \mathrm{~A}$ shows that TOP $2 \alpha / 170$ levels were similar in mock transfected (lipofectamine only) and miRNA mimic control conditions (Fig. 4A). Consistent with our hypothesis, TOP2 $\alpha /$ 170 protein levels were decreased when miR-9-3p or miR-9-5p were overexpressed (Fig. 4A). Averaging results from five separate experiments run on separate days, there was a reduction of TOP $2 \alpha / 170$ levels to $67.6 \%(P<0.001)$ and $49.6 \%(P=0.004)$ of miRNA mimic control in cells treated with miR-9-3p and miR-9-5p, respectively (Fig. 4B).

Etoposide-induced DNA damage correlates most often with levels of the target type II Topoisomerases (Mirski et al., 1993, 2000; Ritke and Yalowich, 1993; Ritke et al., 1994; Harker et al., 1995; Mirski and Cole, 1995; Wessel et al., 1997; Yu et al., 1997; Burgess et al., 2008; Ganapathi and Ganapathi, 2013). Hence, we next investigated whether forced expression of
miR-9-3p and miR-9-5p would diminish etoposide activity in parallel with a reduction in TOP $2 \alpha / 170$ levels (as demonstrated in Fig. 4, A and B). K562 cells were transfected with $25 \mathrm{nM}$ miR9-3p, mir-9-5p, or nontargeting control miRNA mimics. Fortyeight hours after transfection, cells were incubated for 1 hour with etoposide ( 2 or $5 \mu \mathrm{M}$ ) or DMSO vehicle and subsequently evaluated for DNA damage by alkaline single-cell gel electrophoresis (Comet) assays (Kanagasabai et al., 2017, 2018). Etoposide-induced DNA strand breaks were attenuated in miR-9-3p and miR-9-5p mimic-transfected K562 cells compared with control miR-mimic (Fig. 4C). Averaging results from seven experiments run on separate days, there was a reduction in: 1) etoposide $(2 \mu \mathrm{M})$-induced DNA damage to $59.7 \%(P=0.011)$ and $70.7 \%(P=0.025)$ of control and 2$)$ etoposide (5 $\mu \mathrm{M})$-induced DNA damage to $80.7 \%(P=0.006)$ and $77.4 \%(P=0.002)$ of control in K562 cells transfected with miR-9-3p or mir-9-5p mimics, respectively (Fig. 4C). Together these results indicate that forced overexpression of miR-9-3p or miR-9-5p reduces TOP2 $\alpha / 170$ protein expression and, as a consequence, decreases etoposide-mediated DNA damage.

The potential mechanism by which miR-9-3p and miR-9$5 \mathrm{p}$ mimics reduce TOP $2 \alpha / 170$ protein levels was assessed by qPCR. RNA isolated from miR-9-3p and mir-9-5p mimic-transfected K562 cells was used to quantify TOP2 $\alpha /$ 170 mRNA levels. Transfection with miR-9-3p or miR-9-5p mimics did not alter TOP $2 \alpha / 170$ steady-state mRNA levels (Fig. 4D). Therefore, decreased TOP2 $\alpha / 170$ protein expression observed in K562 cells by forced expression of miR-9-3p and miR-9-5p is not due to the degradation of TOP $2 \alpha / 170$ mRNA, suggesting that these miRNAs/miRISC function by blocking the ribosome from translating TOP $2 \alpha / 170$ mRNA.

miR-9-3p and miR-9-5p Inhibitors Increase TOP2 $\alpha$ / 170 Protein and DNA Damage in K/VP.5 Cells. Because the miR-9-3p and miR-9-5p forced expression (gain-ofinhibitory-function) experiments described (Fig. 4) may lead to off-target effects due to supra-physiologic miRNA levels (Fig. 2C) (Bracken et al., 2008; Khan et al., 2009), reciprocal loss-of-miR-9-inhibitory-function experiments were also performed in K/VP.5 cells. Utilizing miRNA inhibitors (chemically modified single stranded antisense nucleic acids designed to bind to and inhibit miRNA function), effects on TOP2 $\alpha / 170$ protein expression and subsequent etoposide-induced DNA damage were evaluated. K/VP.5 cells, which express high levels of miR-9-3p and miR-9-5p (Fig. 2B), were transfected with $25 \mathrm{nM}$ miR-9-3p, miR-9-5p, or control miRNA inhibitors (48 hours), which was followed by immunoblotting of cell lysates to evaluate TOP2 $\alpha / 170$ protein levels. Figure $5 \mathrm{~A}$ shows that TOP2 $\alpha / 170$ protein in K/VP.5 cells was increased after transfection of miR-9$3 p$ and miR-9-5p inhibitors. Averaging results from five separate experiments run on separate days, there was an increase in TOP $2 \alpha / 170$ levels to $261 \%(P=0.035)$ and $256 \%(P=0.027)$ of miRNA inhibitor control in K/VP.5 cells treated with miR-9-3p inhibitor and miR-9-5p, respectively (Fig. 5B).

We next investigated whether transfection of K/VP.5 cells with miR-9-3p and miR-9-5p inhibitors would increase etoposide activity in parallel with the increase in TOP $2 \alpha / 170$ protein levels (as demonstrated in Fig. 5, A and B). K/VP.5 cells were transfected with $25 \mathrm{nM}$ miR-9-3p, miR-9-5p, or control miRNA inhibitors. Forty-eight hours after transfection, cells were incubated for 1 hour with etoposide ( 10 or $25 \mu \mathrm{M}$ ) or DMSO vehicle and subsequently evaluated for DNA damage by alkaline single-cell gel electrophoresis (Comet) assays 
(Kanagasabai et al., 2017, 2018) as above in Fig. 4C. Averaging results from six separate experiments performed on separate days, there was an increase in: 1) etoposide (10 $\mu \mathrm{M})$-induced DNA damage to $147 \%(P=0.002)$ and $147 \%(P=0.001)$ of control and 2) etoposide $(25 \mu \mathrm{M})$-induced DNA damage to $119 \%(P=0.040)$ and $130 \%(P=0.008)$ of control in K/VP.5 cells transfected with miR-9-3p or miR-9-5p inhibitors, respectively (Fig. 5C). Together, results indicate that miR-9-3p and miR-9$5 p$ inhibitors allow for increased TOP $2 \alpha / 170$ protein expression in drug-resistant K/VP.5 cells and, as a consequence, enhance etoposide-induced DNA damage.

Similar to results in miR-9 mimic-transfected K562 cells (Fig. 4D), neither miR-9-3p nor miR-9-5p inhibitor elicited changes in TOP2 $\alpha / 170$ mRNA when transfected in K/VP.5 cells (Fig. 5D), again suggesting that miR-9 effects are not related to alteration in mRNA stability but may impact on translation of TOP $2 \alpha / 170 \mathrm{mRNA}$, in this case by loss of miR-9$3 p$ and miR-9-5p inhibitory activity.

\section{Discussion}

Acquired drug resistance is a major therapeutic challenge in the treatment of cancers. Chemoresistance can result from a number of molecular mechanisms, including aberrant drug transport/trafficking processes, altered drug metabolism, increased or modified drug targets, abnormal cell cycling, cell death evasion, and DNA damage/repair dysregulation (Zahreddine and Borden, 2013; Cree and Charlton, 2017). In recent years, numerous studies have shown that miRNAs can be involved in acquired drug resistance by directly targeting mRNAs that encode proteins regulating the biologic pathways described above (Gabra and Salmena, 2017; Anfossi et al., 2018; Corrà et al., 2018). Our present study focused on whether decreased TOP2 $\alpha / 170$ levels (Fig. 1C) and attenuated etoposide activity in K/VP.5 cells (Fig. 1A) result, in part, from miRNA mechanisms.

miRNA-Seq data revealed that 73 mature miRNAs were overexpressed and 14 miRNAs were repressed in K/VP.5 cells compared with K562 cells (Fig. 2A). Algorithm searches (Agarwal et al., 2015; Paraskevopoulou et al., 2013) suggested that of the 73 overexpressed miRNAs in K/VP. 5 cells, nine miRNAs were predicted to interact with MREs harbored within the TOP2 $\alpha / 170$ mRNA (unpublished data). miR-9-3p and miR-9-5p were highly overexpressed in K/VP.5 cells (Fig. 2A), and MREs were identified in the TOP2 $\alpha / 1703^{\prime}$-UTR (Fig. 2B) for both these miRNAs, leading to further investigation of their function(s).
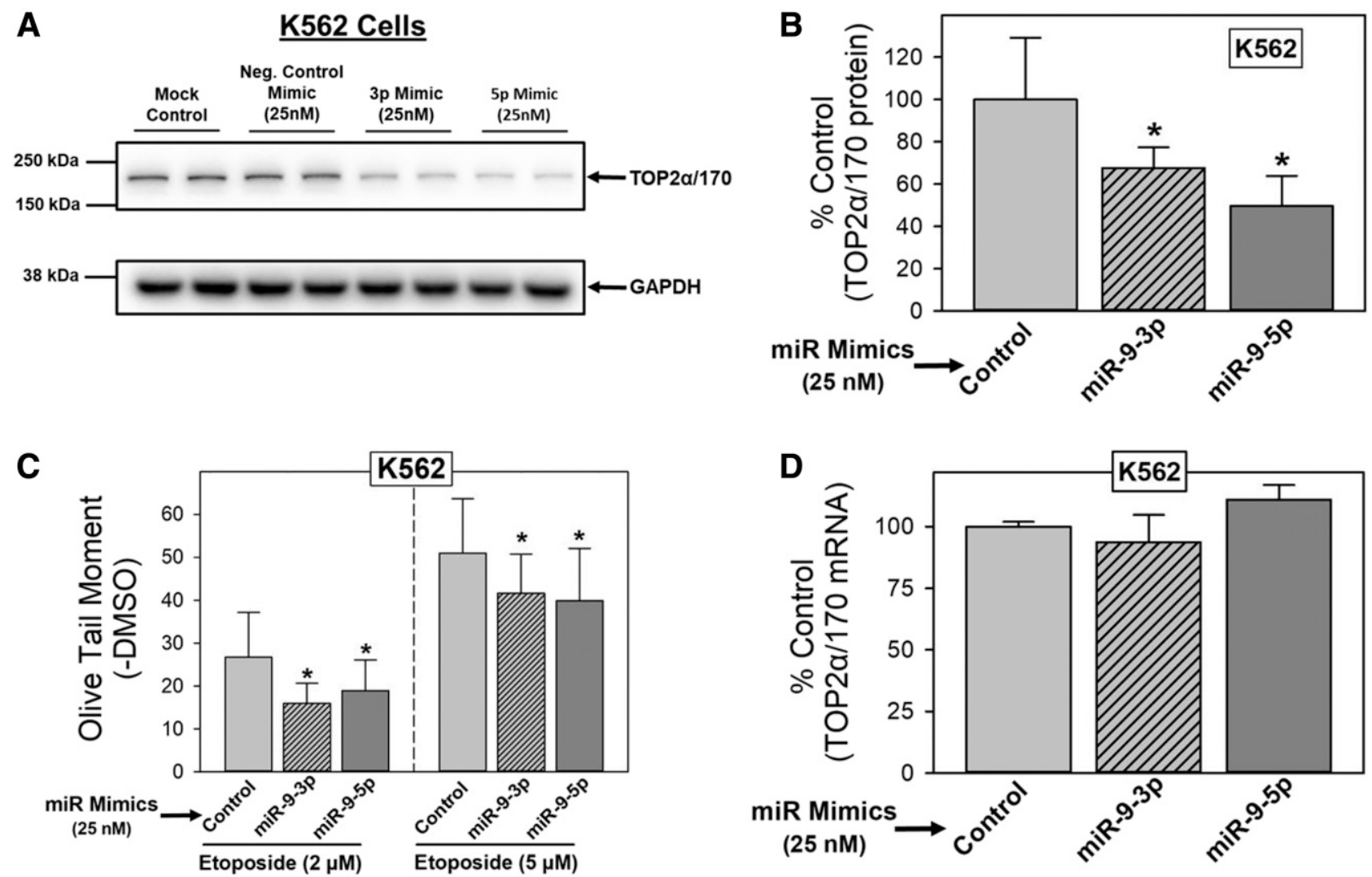

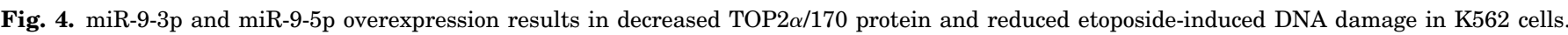

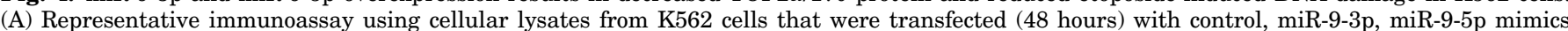

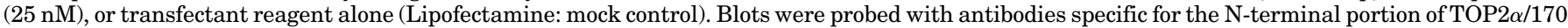

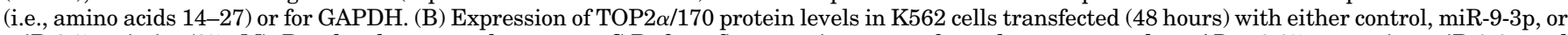

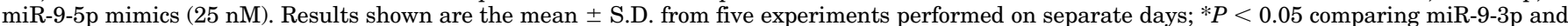

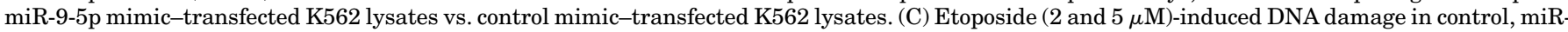

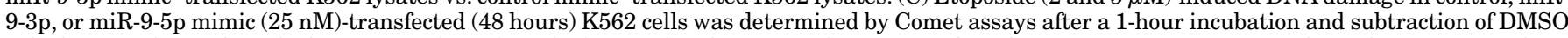

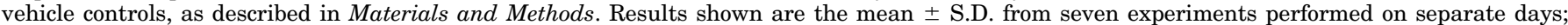

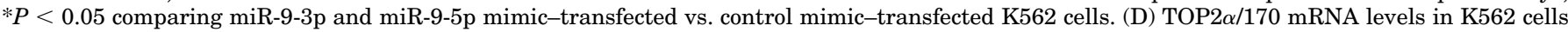

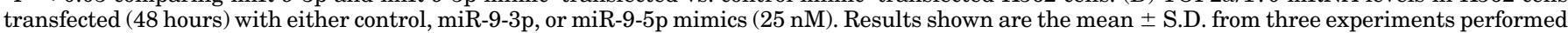
on separate days. 
A

K/VP.5 Cells

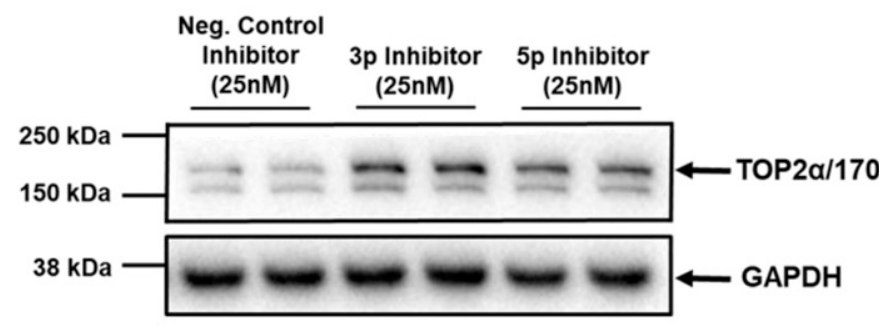

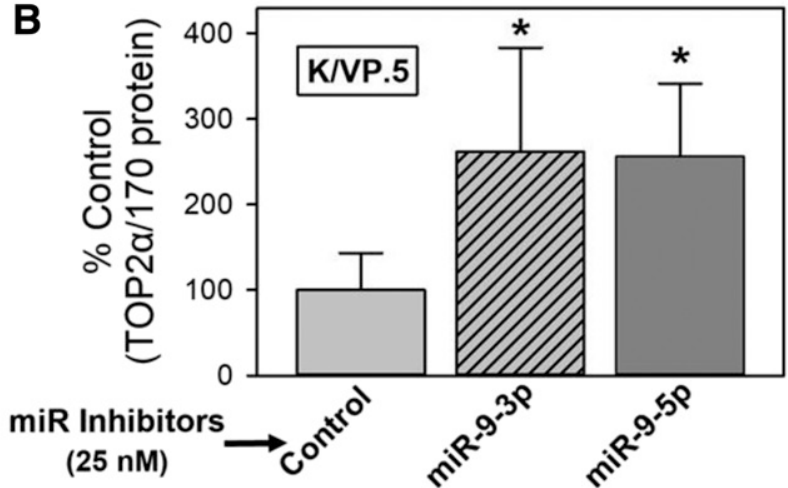

D

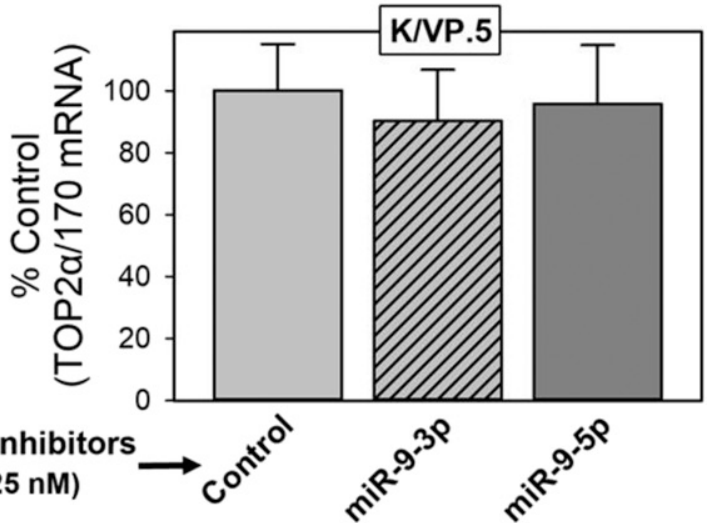

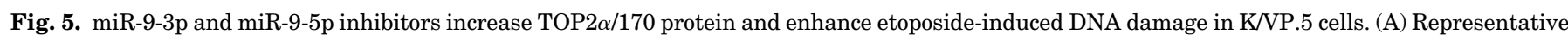

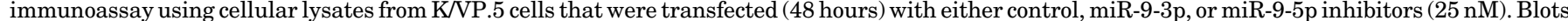

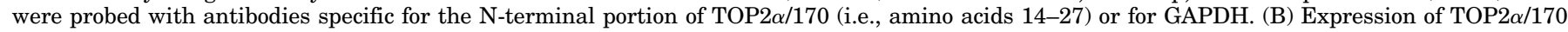

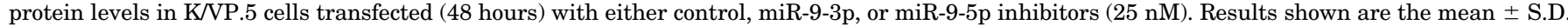

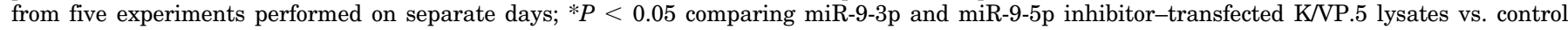

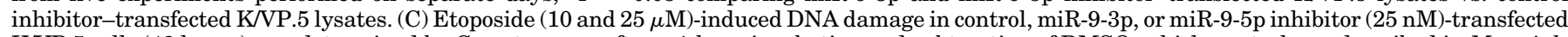

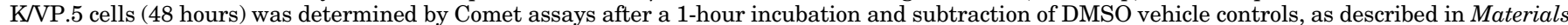

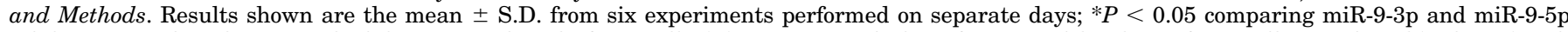

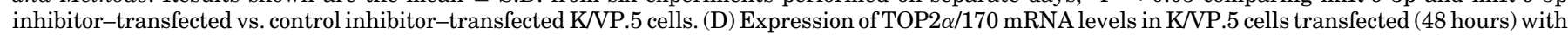
either control, miR-9-3p, or miR-9-5p inhibitors (25 nM). Results shown are the mean \pm S.D. from five experiments performed on separate days.

During RISC loading, the miRNA duplex is bound by a member of the Argonaute protein family, which is followed by strand selection (Treiber et al., 2019). Typically, the strand with the least thermodynamically stable base pair at its $5^{\prime}$ end in the miRNA duplex is selected as the guide strand. The "passenger" strand with the stronger 5 ' end interaction is released and degraded (Schwarz et al., 2003; Khvorova et al., 2003). However, the passenger strand can also be loaded into the miRISC and exhibit inhibitory activity like any other miRNA (Packer et al., 2008). The ratio of Argonaute-loaded 5p or $3 p$ mature strand varies greatly, with coexpression of $5 p / 3 p$ pairs demonstrated in about half of the miRNA populations analyzed (Ro et al., 2007; Kuchenbauer et al., 2011). Such seems to be the case with miR-9-3p and miR-9-5p in K562 and K/VP.5 cells.

Using qPCR, we confirmed miRNA-Seq data (Fig. 2A) to demonstrate overexpression of both miR-9-3p (18.6-fold) and miR-9-5p (12.7-fold) in K/VP.5 compared with K562 cells (Fig. 2C). Additionally, transfection of luciferase constructs containing TOP $2 \alpha / 170$ 3'-UTR established that TOP $2 \alpha / 170$ mRNA is a direct target of both miRNAs (Fig. 3, C and D). Transfection of miR-9 inhibitors increased TOP $2 \alpha / 170$ expression and enhanced etoposide-induced DNA damage in resistant K/VP.5 cells, whereas forced overexpression of both miRNAs in parental K562 cells decreased TOP2 $\alpha / 170$ levels and reduced etoposide activity (Figs. 4 and 5). Because decreased TOP $2 \alpha / 170$ expression is most often associated with resistance (Ganapathi and Ganapathi, 2013), our results strongly suggest that increased expression of miR9-3p and miR-9-5p in K/VP.5 cells are determinants of acquired resistance.

Consistent with our observations of dual expression/ function of miR-9-3p and miR-9-5p, both miRNAs cooperate in regulating the balance between self-renewal and differentiation of human neural stem cells by simultaneously targeting members of the notch pathway (Roese-Koerner et al., 2016). Additionally, miR-9-3p and miR-9-5p can be coexpressed in primary cases of human acute myeloid leukemia (AML) and cotarget erythroblast transformation-specific-related gene mRNA (Nowek et al., 2016). Finally, miR-9-3p and miR-9-5p concurrently target calmodulin-binding transcription activator one mRNA in glioblastoma stem cells (Schraivogel et al., 2011).

Importantly, dysregulation of miR-9-3p and/or miR-9-5p expression has been implicated in a wide range of diseases including cancers (Nass et al., 2009; Barbano et al., 2017; 
Nowek et al., 2018), diabetes (Chakraborty et al., 2014), neurodegenerative diseases (Packer et al., 2008; Juźwik et al., 2019), osteoarthritis (Nugent, 2016), and sporadic premature aging syndromes (Frankel et al., 2018).

Increased levels of miR-9-3p and/or miR-9-5p have been shown to play an important role in mediating chemoresistance (Munoz et al., 2013, 2015b,a). In temozolomide-resistant glioblastoma cells, miR-9-3p and miR-9-5p were overexpressed (Munoz et al., 2015b), miR-9-5p led to increased expression of ABCB1 through activation of the Sonic Hedgehog pathway (Munoz et al., 2015a), and delivery of anti-miR-9-5p decreased ABCB1 and sensitized resistant glioblastoma cells to temozolomide (Munoz et al., 2013).

Conversely, Li et al. (2017) demonstrated that miR-9-3p expression was significantly reduced in Adriamycin (ADR)resistant K562/ADR compared with parental K562 cells. These investigators also established that miR-9-3p targeted $\mathrm{ABCB} 1$ and that transfection of miR-9-3p mimics increased the chemosensitivity of K562/ADR cells. Li et al., 2015 demonstrated that miR-9-5p was down-regulated in both paclitaxel-resistant epithelial ovarian carcinoma (EOC) patient samples and EOC cell lines. Similarly, Sun et al. (2013) established that cisplatin-resistant ovarian cancer patients manifest lower miR-9-5p expression levels. In AML cell lines resistant to daunorubicin, transfection of miR-9-5p mimics enhanced chemosensitivity to daunorubicin by targeting eukaryotic translation initiation factor 5A-2 (Liu et al., 2019). Collectively, this literature indicates that overexpression or underexpression of miR-9-3p or miR-9-5p can play a critical role in chemoresistance depending on cell type. Additionally, these observations support the conclusion that miR-9-3p and/or miR-9-5p act on many mRNA targets important in chemoresistance.

miRISC mediates post-transcriptional silencing of specific mRNAs that contain MREs that are partially or fully complementary to the miRNA (Bartel, 2009). Silencing occurs by target mRNA translational repression and/or mRNA degradation (Fabian and Sonenberg, 2012; Jonas and Izaurralde, 2015). Ribosome profiling studies that compared changes in translational efficiency to changes in mRNA levels demonstrated that the majority of the negative post-transcriptional gene regulatory effects of miRNAs/miRISCs resulted from mRNA degradation (Guo et al., 2010; Eichhorn et al., 2014); true translational repression accounts for only $6 \%-26 \%$ of the decrease of each endogenous target in mammalian cells (Eichhorn et al., 2014).

Our studies demonstrated that there was no reduction in TOP $2 \alpha / 170$ steady-state mRNA levels after transfection of K562 cells with miR-9-3p or miR-9-5p mimics (Fig. 4D), which attenuated TOP $2 \alpha / 170$ protein levels (Fig. 4 , A and B), or after transfection of K/VP.5 cells with miR-9-3p or miR-9-5p inhibitors (Fig. $5 \mathrm{D}$ ), which increased TOP2 $\alpha / 170$ protein levels (Fig. 5, A and B). These results strongly suggest that TOP2 $\alpha / 170$ mRNA is translationally repressed by these miRNAs. In contrast, Hua et al. (2015) demonstrated that TOP2 $\alpha / 170$ mRNA (and protein) was reduced by miR-139 in luminal type breast cancer cells, again pointing to the pleiotropic effects of miRNAs.

Though we conclude that miR-9-3p and miR-9-5p impact translation, steady-state mRNA levels of TOP $2 \alpha / 170$ are reduced in K/VP.5 compared with K562 cells (Fig. 1B) attributable to alternative RNA processing of TOP $2 \alpha / 170$ precursor
mRNA, as we have reported previously (Kanagasabai et al., 2017,2018 ). Hence, reduced TOP $2 \alpha / 170$ protein levels (and acquired drug resistance) can derive from both translational repression (via miRNA mechanisms) and aberrant precursor mRNA processing.

Given that three distinct MIR9 genes transcribe primary transcripts processed into identical mature miR-9-3p and miR-9-5p miRNAs (Yuva-Aydemir et al., 2011), we performed qPCR experiments to investigate whether MIR9-1, MIR9-2, MIR9-3, or a combination of these genes was significantly up-regulated in etoposide-resistant K/VP.5 cells. Interestingly, only pri-miR-9-1 was significantly upregulated in K/VP.5 cells (Fig. 2D); likely leading to the observed increase in mature miR-9-3p and miR-9-5p expression levels.

It is not clear how MIR9-1 gene expression is activated in K/VP.5 cells. However, because the promoters of all three MIR9 genes are embedded within CpG islands, they are frequently aberrantly hypomethylated or hypermethylated in cancer (Kunej et al., 2011; Suzuki et al., 2013). Li et al., 2015 established that the MIR9-1 and MIR9-3 genes were hypermethylated in paclitaxel-resistant EOC cell lines, suggesting that decreased miR-9-5p expression resulted from aberrant DNA methylation. Recently, Fu et al. (2017) demonstrated that the MIR9-1 gene underwent heterochromatic silencing by the binding of the runt-related family transcription factor 1 (RUNX1) to the MIR9-1 promoter region and recruitment of chromatin-remodeling enzymes that resulted in the hypermethylation of MIR9-1 in t(8;21) AML. Given that RUNX1 is a direct target of both miR-9-3p and miR-9-5p (Tian et al., 2015; Raghuwanshi et al., 2018; TargetScan), we speculate that that the observed increase in MIR9-1 gene expression in etoposide-resistant K/VP.5 cells may result from the hypomethylation of the MIR9-1 promoter due to decreased RUNX1 expression and the subsequent lack of recruitment of chromatin-remodeling enzymes. Future experiments will test this hypothesis.

In conclusion, TOP $2 \alpha / 170$ is an established therapeutic target, the expression levels of which are important for the efficacy of topoisomerase II-targeted drugs. Hence, it is critical to understand the mechanisms by which TOP $2 \alpha / 170$ expression is regulated, especially in acquired drug resistance. Results demonstrated that miR-9-3p and miR-9-5p were overexpressed in etoposide-resistant K/VP.5 cells and regulated the expression of TOP $2 \alpha / 170$, likely through inhibition of translation. Additionally, miR-9-3p and miR-9-5p impact etoposide-induced DNA damage secondary to effects on TOP $2 \alpha / 170$ levels. This functional aspect of both miR-9-3p and miR-9-5p with regards to chemoresistance demonstrates their potential as drug targets for and/or biomarkers of resistance to TOP $2 \alpha$ interfacial inhibitors.

Future studies aim to validate miR-9-3p and miR-9-5p as biomarkers of chemoresistance by analyzing expression in cells from newly diagnosedand relapsed leukemia patients who received TOP $2 \alpha / 170$-targeted agents as well as establish the in vivo effects of these miRNAs on etoposide efficacy in xenograft models of leukemia.

\section{Acknowledgments}

The authors thank Dr. Junan Li, The Ohio State University College of Pharmacy, for excellent biostatistical support. 


\section{Authorship Contributions}

Participated in research design: Kania, Carvajal-Moreno, Hernandez,

English, Papa, Ozer, Yalowich, Elton.

Conducted experiments: Kania, Carvajal-Moreno, Hernandez,

English, Papa, Shkolnikov.

Contributed new reagents or analytical tools: Kania, Ozer.

Performed data analysis: Kania, Carvajal-Moreno, Hernandez,

English, Papa, Shkolnikov, Ozer, Yilmaz, Yalowich, Elton.

Wrote or contributed to the writing of the manuscript: Kania,

Hernandez, Ozer, Yalowich, Elton.

\section{References}

Agarwal V, Bell GW, Nam JW, and Bartel DP (2015) Predicting effective microRNA target sites in mammalian mRNAs. Elife 4:1-38.

Anfossi S, Fu X, Nagvekar R, and Calin GA (2018) MicroRNAs, regulatory messengers inside and outside cancer cells. Adv Exp Med Biol 1056:87-108.

Ashour ME, Atteya R, and El-Khamisy SF (2015) Topoisomerase-mediated chromosomal break repair: an emerging player in many games. Nat Rev Cancer 15: 137-151.

Barbano R, Pasculli B, Rendina M, Fontana A, Fusilli C, Copetti M, Castellana S, Valori VM, Morritti M, Graziano P, et al. (2017) Stepwise analysis of MIR9 loci identifies miR-9-5p to be involved in Oestrogen regulated pathways in breast cancer patients. Sci Rep 7:45283.

Bartel DP (2009) MicroRNAs: target recognition and regulatory functions. Cell 136: 215-233.

Bracken CP, Gregory PA, Kolesnikoff N, Bert AG, Wang J, Shannon MF, and Goodall GJ (2008) A double-negative feedback loop between ZEB1-SIP1 and the microRNA200 family regulates epithelial-mesenchymal transition. Cancer Res 68:7846-7854. Broughton JP, Lovci MT, Huang JL, Yeo GW, and Pasquinelli AE (2016) Pairing beyond the seed supports MicroRNA targeting specificity. Mol Cell 64:320-333.

Bugg BY, Danks MK, Beck WT, and Suttle DP (1991) Expression of a mutant DNA topoisomerase II in CCRF-CEM human leukemic cells selected for resistance to teniposide. Proc Natl Acad Sci USA 88:7654-7658.

Burgess DJ, Doles J, Zender L, Xue W, Ma B, McCombie WR, Hannon GJ, Lowe SW, and Hemann MT (2008) Topoisomerase levels determine chemotherapy response in vitro and in vivo. Proc Natl Acad Sci USA 105:9053-9058.

Bushati N and Cohen SM (2007) microRNA functions. Annu Rev Cell Dev Biol 23: 175-205.

Chakraborty C, Doss CG, Bandyopadhyay S, and Agoramoorthy G (2014) Influence of miRNA in insulin signaling pathway and insulin resistance: micro-molecules with a major role in type-2 diabetes. Wiley Interdiscip Rev RNA 5:697-712.

Chen AY and Liu LF (1994) Mechanisms of resistance to topoisomerase inhibitors. Cancer Treat Res 73:263-281.

Chen SH, Chan NL, and Hsieh TS (2013) New mechanistic and functional insights into DNA topoisomerases. Annu Rev Biochem 82:139-170.

Corrà F, Agnoletto C, Minotti L, Baldassari F, and Volinia S (2018) The network of non-coding RNAs in cancer drug resistance. Front Oncol 8:327.

Cree IA and Charlton P (2017) Molecular chess? Hallmarks of anti-cancer drug resistance. BMC Cancer 17:10.

Deweese JE and Osheroff N (2009) The DNA cleavage reaction of topoisomerase II: wolf in sheep's clothing. Nucleic Acids Res 37:738-748.

Eichhorn SW, Guo H, McGeary SE, Rodriguez-Mias RA, Shin C, Baek D, Hsu SH Ghoshal K, Villén J, and Bartel DP (2014) mRNA destabilization is the dominant effect of mammalian microRNAs by the time substantial repression ensues. $\mathrm{Mol}$ Cell 56:104-115.

Elton TS and Yalowich JC (2015) Experimental procedures to identify and validate specific mRNA targets of miRNAs. EXCLI $J$ 14:758-790.

Fabian MR and Sonenberg N (2012) The mechanics of miRNA-mediated gene silencing: a look under the hood of miRISC. Nat Struct Mol Biol 19:586-593.

Frankel D, Delecourt V, Harhouri K, De Sandre-Giovannoli A, Lévy N, Kaspi E, and Roll P (2018) MicroRNAs in hereditary and sporadic premature aging syndromes and other laminopathies. Aging Cell 17:e12766.

Fu L, Shi J, Liu A, Zhou L, Jiang M, Fu H, Xu K, Li D, Deng A, Zhang Q, et al. (2017) A minicircuitry of microRNA-9-1 and RUNX1-RUNX1T1 contributes to leukemogenesis in $\mathrm{t}(8 ; 21)$ acute myeloid leukemia. Int J Cancer 140:653-661.

Gabra MM and Salmena L (2017) microRNAs and acute myeloid leukemia chemoresistance: a mechanistic overview. Front Oncol 7:255.

Ganapathi RN and Ganapathi MK (2013) Mechanisms regulating resistance to inhibitors of topoisomerase II. Front Pharmacol 4:89.

Ganger MT, Dietz GD, and Ewing SJ (2017) A common base method for analysis of qPCR data and the application of simple blocking in qPCR experiments. BMC Bioinformatics 18:534.

Griffiths-Jones S (2004) The microRNA Registry. Nucleic Acids Res 32:D109-D111.

Guo H, Ingolia NT, Weissman JS, and Bartel DP (2010) Mammalian microRNAs predominantly act to decrease target mRNA levels. Nature 466:835-840.

Gyori BM, Venkatachalam G, Thiagarajan PS, Hsu D, and Clement MV (2014) OpenComet: an automated tool for comet assay image analysis. Redox Biol 2: $457-465$.

Ha M and Kim VN (2014) Regulation of microRNA biogenesis. Nat Rev Mol Cell Biol 15:509-524.

Harker WG, Slade DL, Parr RL, and Holguin MH (1995) Selective use of an alternative stop codon and polyadenylation signal within intron sequences leads to a truncated topoisomerase II alpha messenger RNA and protein in human HL-60 leukemia cells selected for resistance to mitoxantrone. Cancer Res 55:4962-4971.

Hinds M, Deisseroth K, Mayes J, Altschuler E, Jansen R, Ledley FD, and Zwelling LA (1991) Identification of a point mutation in the topoisomerase II gene from a human leukemia cell line containing an amsacrine-resistant form of topoisomerase II. Cancer Res 51:4729-4731.

Hua W, Sa KD, Zhang X, Jia LT, Zhao J, Yang AG, Zhang R, Fan J, and Bian K (2015) MicroRNA-139 suppresses proliferation in luminal type breast cancer cells by targeting Topoisomerase II alpha. Biochem Biophys Res Commun 463:1077-1083.

Jonas S and Izaurralde E (2015) Towards a molecular understanding of microRNAmediated gene silencing. Nat Rev Genet 16:421-433.

Juźwik CA, Drake SS, Zhang Y, Paradis-Isler N, Sylvester A, Amar-Zifkin A, Douglas C, Morquette B, Moore CS, and Fournier A (2019) microRNA dysregulation in neurodegenerative diseases: a systematic review. Prog Neurobiol 182:101664.

Kanagasabai R, Karmahapatra S, Kientz CA, Yu Y, Hernandez VA, Kania EE, Yalowich JC, and Elton TS (2018) The novel C-terminal truncated 90-kDa isoform of topoisomerase II $\alpha$ (TOP2 $\alpha / 90$ ) is a determinant of etoposide resistance in K562 leukemia cells via heterodimerization with the TOP $2 \alpha / 170$ isoform. Mol Pharmacol 93:515-525.

Kanagasabai R, Serdar L, Karmahapatra S, Kientz CA, Ellis J, Ritke MK, Elton TS, and Yalowich JC (2017) Alternative RNA processing of topoisomerase II $\alpha$ in etoposide-resistant human leukemia K562 cells: intron retention results in a novel C-terminal truncated 90-kDa isoform. J Pharmacol Exp Ther 360:152-163.

Khan AA, Betel D, Miller ML, Sander C, Leslie CS, and Marks DS (2009) Transfection of small RNAs globally perturbs gene regulation by endogenous microRNAs. Nat Biotechnol 27:549-555.

Khvorova A, Reynolds A, and Jayasena SD (2003) Functional siRNAs and miRNAs exhibit strand bias. Cell 115:209-216.

Kubo A, Yoshikawa A, Hirashima T, Masuda N, Takada M, Takahara J, Fukuoka M, and Nakagawa K (1996) Point mutations of the topoisomerase IIalpha gene in patients with small cell lung cancer treated with etoposide. Cancer Res 56: 1232-1236.

Kuchenbauer F, Mah SM, Heuser M, McPherson A, Rüschmann J, Rouhi A, Berg T, Bullinger L, Argiropoulos B, Morin RD, et al. (2011) Comprehensive analysis of mammalian miRNA* species and their role in myeloid cells. Blood 118:3350-3358.

Kuhn DE, Martin MM, Feldman DS, Terry AV Jr, Nuovo GJ, and Elton TS (2008) Experimental validation of miRNA targets. Methods 44:47-54.

Kunej T, Godnic I, Ferdin J, Horvat S, Dovc P, and Calin GA (2011) Epigenetic regulation of microRNAs in cancer: an integrated review of literature. Mutat Res 717:77-84

Langmead B, Trapnell C, Pop M, and Salzberg SL (2009) Ultrafast and memoryefficient alignment of short DNA sequences to the human genome. Genome Biol 10: R25.

Laponogov I, Pan XS, Veselkov DA, McAuley KE, Fisher LM, and Sanderson MR (2010) Structural basis of gate-DNA breakage and resealing by type II topoisomerases. PLoS One 5:e11338.

Larsen AK, Escargueil AE, and Skladanowski A (2003) Catalytic topoisomerase II inhibitors in cancer therapy. Pharmacol Ther 99:167-181.

Li H, Handsaker B, Wysoker A, Fennell T, Ruan J, Homer N, Marth G, Abecasis G, and Durbin R; 1000 Genome Project Data Processing Subgroup (2009) The sequence alignment/map format and SAMtools. Bioinformatics 25:2078-2079.

Li X, Pan Q, Wan X, Mao Y, Lu W, Xie X, and Cheng X (2015) Methylation-associated Hsa-miR-9 deregulation in paclitaxel- resistant epithelial ovarian carcinoma. BMC Cancer 15:509.

Li Y, Zhao L, Li N, Miao Y, Zhou H, and Jia L (2017) miR-9 regulates the multidrug resistance of chronic myelogenous leukemia by targeting ABCB1. Oncol Rep 37: $2193-2200$

Liao Y, Smyth GK, and Shi W (2014) featureCounts: an efficient general purpose program for assigning sequence reads to genomic features. Bioinformatics $\mathbf{3 0}$ 923-930.

Liu Y, Lei P, Qiao H, Sun K, Lu X, Bao F, Yu R, Lian C, Li Y, Chen W, et al. (2019) miR-9 enhances the chemosensitivity of AML cells to daunorubicin by targeting the EIF5A2/MCL-1 axis. Int J Biol Sci 15:579-586.

Martin M (2011) Cutadapt removes adapter sequences from high-throughput sequencing reads. EMBnet $J$ 17:10-12.

Mirski SE and Cole SP (1995) Cytoplasmic localization of a mutant M(r) 160,000 topoisomerase II alpha is associated with the loss of putative bipartite nuclear localization signals in a drug-resistant human lung cancer cell line. Cancer Res $\mathbf{5 5}$ $2129-2134$

Mirski SE, Evans CD, Almquist KC, Slovak ML, and Cole SP (1993) Altered topoisomerase II alpha in a drug-resistant small cell lung cancer cell line selected in VP-16. Cancer Res 53:4866-4873.

Mirski SE, Sparks KE, Yu Q, Lang AJ, Jain N, Campling BG, and Cole SP (2000) A truncated cytoplasmic topoisomerase IIalpha in a drug-resistant lung cancer cell line is encoded by a TOP2A allele with a partial deletion of exon 34. Int J Cancer 85:534-539.

Munoz JL, Bliss SA, Greco SJ, Ramkissoon SH, Ligon KL, and Rameshwar P (2013) Delivery of functional anti-miR-9 by mesenchymal stem cell-derived exosomes to glioblastoma multiforme cells conferred chemosensitivity. Mol Ther Nucleic Acids 2.e126.

Munoz JL, Rodriguez-Cruz V, and Rameshwar P (2015b) High expression of miR-9 in $\mathrm{CD}_{133^{+}}$glioblastoma cells in chemoresistance to temozolomide. J Cancer Stem Cell Res 3:1-14.

Munoz JL, Rodriguez-Cruz V, Ramkissoon SH, Ligon KL, Greco SJ, and Rameshwar $\mathrm{P}$ (2015a) Temozolomide resistance in glioblastoma occurs by miRNA-9targeted PTCH1, independent of sonic hedgehog level. Oncotarget 6 1190-1201.

Nass D, Rosenwald S, Meiri E, Gilad S, Tabibian-Keissar H, Schlosberg A, Kuker H, Sion-Vardy N, Tobar A, Kharenko O, et al. (2009) MiR-92b and miR-9/9* are specifically expressed in brain primary tumors and can be used to differentiate primary from metastatic brain tumors. Brain Pathol 19:375-383.

Nitiss JL (2009) Targeting DNA topoisomerase II in cancer chemotherapy. Nat Rev Cancer 9:338-350.

Nowek K, Sun SM, Bullinger L, Bindels EM, Exalto C, Dijkstra MK, van Lom K, Döhner H, Erkeland SJ, Löwenberg B, et al. (2016) Aberrant expression of 
miR-9/9* in myeloid progenitors inhibits neutrophil differentiation by posttranscriptional regulation of ERG. Leukemia 30:229-237.

Nowek K, Wiemer EAC, and Jongen-Lavrencic M (2018) The versatile nature of miR 9/9* in human cancer. Oncotarget 9:20838-20854

Nugent M (2016) MicroRNAs: exploring new horizons in osteoarthritis. Osteoarthritis Cartilage 24:573-580.

Olive PL (2002) The comet assay. An overview of techniques. Methods Mol Biol 203: 179-194.

Packer AN, Xing Y, Harper SQ, Jones L, and Davidson BL (2008) The bifunctional microRNA miR-9/miR-9* regulates REST and CoREST and is downregulated in Huntington's disease. $J$ Neurosci 28:14341-14346.

Paraskevopoulou MD, Georgakilas G, Kostoulas N, Vlachos IS, Vergoulis T, Reczko M, Filippidis C, Dalamagas T, and Hatzigeorgiou AG (2013) DIANA-microT web server v5.0: service integration into miRNA functional analysis workflows. Nucleic Acids Res 41:W169-W173.

Pendleton M, Lindsey RH Jr, Felix CA, Grimwade D, and Osheroff N (2014) Topoisomerase II and leukemia. Ann N Y Acad Sci 1310:98-110.

Pilati P, Nitti D, and Mocellin S (2012) Cancer resistance to type II topoisomerase inhibitors. Curr Med Chem 19:3900-3906.

Pommier Y, Leo E, Zhang H, and Marchand C (2010) DNA topoisomerases and their poisoning by anticancer and antibacterial drugs. Chem Biol 17:421-433.

Raghuwanshi S, Gutti U, Kandi R, and Gutti RK (2018) MicroRNA-9 promotes cell proliferation by regulating RUNX1 expression in human megakaryocyte development. Cell Prolif 51:e12414.

Ritchie ME, Phipson B, Wu D, Hu Y, Law CW, Shi W, and Smyth GK (2015) Limma powers differential expression analyses for RNA-sequencing and microarray studies. Nucleic Acids Res 43:e47.

Ritke MK and Yalowich JC (1993) Altered gene expression in human leukemia K562 cells selected for resistance to etoposide. Biochem Pharmacol 46:2007-2020.

Ritke MK, Roberts D, Allan WP, Raymond J, Bergoltz VV, and Yalowich JC (1994) Altered stability of etoposide-induced topoisomerase II-DNA complexes in resistant human leukaemia K562 cells. Br J Cancer 69:687-697.

Ro S, Park C, Young D, Sanders KM, and Yan W (2007) Tissue-dependent paired expression of miRNAs. Nucleic Acids Res 35:5944-5953.

Roese-Koerner B, Stappert L, Berger T, Braun NC, Veltel M, Jungverdorben J, Evert BO, Peitz M, Borghese L, and Brüstle O (2016) Reciprocal regulation between bifunctional miR-9/9 $*)$ and its transcriptional modulator notch in human neural stem cell self-renewal and differentiation. Stem Cell Reports 7:207-219.

Sansom SE, Nuovo GJ, Martin MM, Kotha SR, Parinandi NL, and Elton TS (2010) miR-802 regulates human angiotensin II type 1 receptor expression in intestinal epithelial C2BBe1 cells. Am J Physiol Gastrointest Liver Physiol 299:G632-G642.

Schmittgen TD and Livak KJ (2008) Analyzing real-time PCR data by the comparative $\mathrm{C}(\mathrm{T})$ method. Nat Protoc 3:1101-1108.

Schraivogel D, Weinmann L, Beier D, Tabatabai G, Eichner A, Zhu JY, Anton M, Sixt M, Weller M, Beier CP, et al. (2011) CAMTA1 is a novel tumour suppressor regulated by miR-9/9* in glioblastoma stem cells. EMBO J 30:4309-4322.
Schwarz DS, Hutvágner G, Du T, Xu Z, Aronin N, and Zamore PD (2003) Asymmetry in the assembly of the RNAi enzyme complex. Cell 115:199-208.

Sun C, Li N, Yang Z, Zhou B, He Y, Weng D, Fang Y, Wu P, Chen P, Yang X, et al. (2013) miR-9 regulation of BRCA1 and ovarian cancer sensitivity to cisplatin and PARP inhibition. J Natl Cancer Inst 105:1750-1758.

Suzuki H, Maruyama R, Yamamoto E, and Kai M (2013) Epigenetic alteration and microRNA dysregulation in cancer. Front Genet 4:258.

Tian J, Rui K, Tang X, Ma J, Wang Y, Tian X, Zhang Y, Xu H, Lu L, and Wang S (2015) MicroRNA-9 regulates the differentiation and function of myeloid-derived suppressor cells via targeting Runx1. J Immunol 195:1301-1311.

Treiber T, Treiber N, and Meister G (2019) Regulation of microRNA biogenesis and its crosstalk with other cellular pathways. Nat Rev Mol Cell Biol 20:5-20.

Vassetzky YS, Alghisi GC, and Gasser SM (1995) DNA topoisomerase II mutations and resistance to anti-tumor drugs. BioEssays 17:767-774.

Vlasova II, Feng WH, Goff JP, Giorgianni A, Do D, Gollin SM, Lewis DW, Kagan VE, and Yalowich JC (2011) Myeloperoxidase-dependent oxidation of etoposide in human myeloid progenitor CD34+ cells. Mol Pharmacol 79:479-487.

Vos SM, Tretter EM, Schmidt BH, and Berger JM (2011) All tangled up: how cells direct, manage and exploit topoisomerase function. Nat Rev Mol Cell Biol 12 827-841.

Wessel I, Jensen PB, Falck J, Mirski SE, Cole SP, and Sehested M (1997) Loss of amino acids 1490Lys-Ser-Lys1492 in the COOH-terminal region of topoisomerase IIalpha in human small cell lung cancer cells selected for resistance to etoposide results in an extranuclear enzyme localization. Cancer Res 57: 4451-4454.

Yu Q, Mirski SE, Sparks KE, and Cole SP (1997) Two COOH-terminal truncated cytoplasmic forms of topoisomerase II alpha in a VP-16-selected lung cancer cell line result from partial gene deletion and alternative splicing. Biochemistry $\mathbf{3 6}$ 5868-5877.

Yuva-Aydemir Y, Simkin A, Gascon E, and Gao FB (2011) MicroRNA-9: functional evolution of a conserved small regulatory RNA. RNA Biol 8:557-564.

Zahreddine $\mathrm{H}$ and Borden KL (2013) Mechanisms and insights into drug resistance in cancer. Front Pharmacol 4:28.

Zwelling LA, Hinds M, Chan D, Mayes J, Sie KL, Parker E, Silberman L, Radcliffe A, Beran M, and Blick M (1989) Characterization of an amsacrine-resistant line of human leukemia cells. Evidence for a drug-resistant form of topoisomerase II. J Biol Chem 264:16411-16420.

Address correspondence to: Jack C. Yalowich, Division of Pharmaceutics and Pharmacology, College of Pharmacy, The Ohio State University, 500 West 12th Avenue, Columbus, OH 43210. E-mail: yalowich.1@osu.edu; or Terry S. Elton, Division of Pharmaceutics and Pharmacology, College of Pharmacy, The Ohio State University, 500 West 12th Avenue, Columbus, OH 43210. E-mail: elton.8@osu.edu 